OPEN ACCESS

Edited by:

Jeremy Astier,

Helmholtz Zentrum München Deutsches Forschungszentrum für Gesundheit und Umwelt, Germany

Reviewed by:

Costas Delis,

Technological Educational Institute

of Peloponnese, Greece

Shabir Hussain Wani, Michigan State University,

United States

Zonghua Wang,

Fujian Agriculture and

Forestry University, China

*Correspondence:

Jeffrey W. Cary

jeff.cary@ars.usda.gov

Specialty section:

This article was submitted to

Plant Microbe Interactions,

a section of the journal

Frontiers in Plant Science

Received: 29 September 2017

Accepted: 27 February 2018

Published: 20 March 2018

Citation:

Majumdar R, Lebar M, Mack B, Minocha $R$, Minocha $S$,

Carter-Wienties C, Sickler C,

Rajasekaran K and Cary JW (2018)

The Aspergillus flavus Spermidine

Synthase (spds) Gene, Is Required

for Normal Development, Aflatoxin

Production, and Pathogenesis During

Infection of Maize Kernels.

Front. Plant Sci. 9:317.

doi: 10.3389/fpls.2018.00317

\section{The Aspergillus flavus Spermidine Synthase (spds) Gene, Is Required for Normal Development, Aflatoxin Production, and Pathogenesis During Infection of Maize Kernels}

\author{
Rajtilak Majumdar ${ }^{1}$, Matt Lebar ${ }^{1}$, Brian Mack', Rakesh Minocha², Subhash Minocha ${ }^{3}$, \\ Carol Carter-Wientjes ${ }^{1}$, Christine Sickler ${ }^{1}$, Kanniah Rajasekaran ${ }^{1}$ and Jeffrey W. Cary ${ }^{1 *}$ \\ ${ }^{1}$ Food and Feed Safety Research Unit, United States Department of Agriculture, Agricultural Research Service, \\ Southern Regional Research Center, New Orleans, LA, United States, ${ }^{2}$ United States Department of Agriculture Forest \\ Service, Northern Research Station, Durham, NH, United States, ${ }^{3}$ Department of Biological Sciences, University of New \\ Hampshire, Durham, NH, United States
}

Aspergillus flavus is a soil-borne saprophyte and an opportunistic pathogen of both humans and plants. This fungus not only causes disease in important food and feed crops such as maize, peanut, cottonseed, and tree nuts but also produces the toxic and carcinogenic secondary metabolites (SMs) known as aflatoxins. Polyamines (PAs) are ubiquitous polycations that influence normal growth, development, and stress responses in living organisms and have been shown to play a significant role in fungal pathogenesis. Biosynthesis of spermidine (Spd) is critical for cell growth as it is required for hypusination-mediated activation of eukaryotic translation initiation factor 5A (elF5A), and other biochemical functions. The tri-amine Spd is synthesized from the diamine putrescine (Put) by the enzyme spermidine synthase (Spds). Inactivation of spds resulted in a total loss of growth and sporulation in vitro which could be partially restored by addition of exogenous Spd. Complementation of the $\Delta$ spds mutant with a wild type (WT) A. flavus spds gene restored the WT phenotype. In WT A. flavus, exogenous supply of Spd (in vitro) significantly increased the production of sclerotia and SMs. Infection of maize kernels with the $\Delta s p d s$ mutant resulted in a significant reduction in fungal growth, sporulation, and aflatoxin production compared to controls. Quantitative PCR of $\Delta$ spds mutant infected seeds showed down-regulation of aflatoxin biosynthetic genes in the mutant compared to WT A. flavus infected seeds. Expression analyses of PA metabolism/transport genes during $A$. flavus-maize interaction showed significant increase in the expression of arginine decarboxylase (Adc) and S-adenosylmethionine decarboxylase (Samdc) genes in the maize host and PA uptake transporters in the fungus. The results presented here demonstrate that Spd biosynthesis is critical for normal development and pathogenesis of $A$. flavus and pre-treatment of a $\Delta s p d s$ mutant with Spd or Spd uptake from the host plant, are insufficient to restore WT levels 
of pathogenesis and aflatoxin production during seed infection. The data presented here suggest that future studies targeting spermidine biosynthesis in A. flavus, using RNA interference-based host-induced gene silencing approaches, may be an effective strategy to reduce aflatoxin contamination in maize and possibly in other susceptible crops.

\section{Keywords: Aspergillus flavus, spermidine synthase, polyamines, aflatoxin, mycotoxin, polyamine uptake,} amino acids

\section{INTRODUCTION}

Mycotoxin contamination in food and feed crops is a global problem. Exposure to mycotoxins primarily occurs through the consumption of contaminated seeds/edible plant parts by humans and livestock. The majority of mycotoxin contamination in crop plants comes from the fungal genera, Aspergillus, Fusarium, and Penicillium, with Aspergillus causing the greatest adverse economic and health impacts (Ismaiel and Papenbrock, 2015; Mitchell et al., 2016; Umesha et al., 2016). Maize is a major food and feed crop grown worldwide and is susceptible to Aspergillus flavus infection and subsequent contamination with aflatoxins and other toxic SMs thus posing a serious threat to food security worldwide (Mitchell et al., 2016; Umesha et al., 2016). Contamination of crops with aflatoxins has been shown to be intensified during episodes of drought (Kebede et al., 2012; Fountain et al., 2014). Increases in aflatoxin contamination in maize during episodes of drought and heat stress is believed to be due to the response of $A$. flavus to increased oxidative stress as well as impairment of host plant defense responses (Fountain et al., 2014, 2016). Although drought tolerance alone does not necessarily result in increased aflatoxin resistance in maize, drought tolerance accompanied with aflatoxin resistance would be ideal in reducing aflatoxin accumulation in maize during drought (Hamidou et al., 2014; Farfan et al., 2015; Fountain et al., 2015). Aflatoxin contamination in maize results in economic losses of almost $\$ 700$ million/year in the U.S. based on a study conducted in 2013 (Mitchell et al., 2016). Based on global climate change predictions, it is estimated that losses resulting from aflatoxin contamination of maize could be as high as US $\$ 1.68$ billion/year in the United States. (Mitchell et al., 2016). Given the adverse impacts of aflatoxins to humans and livestock, preharvest control might be the best way to prevent aflatoxin contamination in food and feed commodities. Methods for preharvest control of aflatoxin contamination in maize include, (i) introduction of resistance genes against A. flavus; (ii) rational design of inhibitors of fungal biochemical pathways/enzymes required for aflatoxin production; (iii) biological control; and (iv) use of modern functional genomics tools to inhibit expression

Abbreviations: AA, amino acid; Adc, arginine decarboxylase; Ala, alanine; Arg, arginine; Asp, aspartate; Cys, cysteine; Dao, diamine oxidase; GABA, $\gamma$-aminobutyric acid; Glu, glutamate; Gly, glycine; His, histidine; Ile, isoleucine; Leu, leucine; Lys, lysine; Odc, ornithine decarboxylase; Orn, ornithine; PA, polyamine; Pao, polyamine oxidase; PCA, perchloric acid; Pro, proline; Put, putrescine; Samdc, S-adenosylmethionine decarboxylase; Ser, serine; SM, secondary metabolite; Spd, spermidine; Spds, spermidine synthase; Spm, spermine; Spms, spermine synthase; Thr, threonine; Trp, tryptophan; Val, valine; WT, wildtype. of fungal genes critical to maize colonization and aflatoxin production.

A number of candidate fungal genes have been targeted to control plant disease including PA metabolic genes (ValdésSantiago et al., 2012; Liao et al., 2015; Jasso-Robles et al., 2016). PAs are ubiquitous, small aliphatic, poly-cationic, biogenic amines of wide-spread occurrence throughout all life forms. They are involved in plethora of cellular processes in living organisms including interactions with DNA (replication, transcription, and translation), transporter function, scavenging of oxidative stress molecules, growth and development, and stress response (reviewed in Valdés-Santiago et al., 2012; Valdés-Santiago and Ruiz-Herrera, 2013; Minocha et al., 2014; Miller-Fleming et al., 2015; Masson et al., 2017). The three predominant PAs widely found in living organisms are, Put (diamine), Spd (tri-amine), and Spm (tetramine). The diamine Put is produced by Odc (E.C.4.1.1.17) from Orn and/or by Adc (EC 4.1.1.19) from Arg. Higher PAs, Spd, and Spm are synthesized by the action of Spds (E.C.2.5.1.16) and Spms (E.C.2.5.1.22) from Put and Spm, respectively (reviewed in Shao et al., 2012). Both reactions require decarboxylated $S$-adenosylmethionine (dcSAM) that is produced by Samdc (E.C.4.1.1.50). Spm and Spd on the other hand can be back-converted to Spd and Put, respectively, by Spd/Spm N1-acetyltransferase (Sat; E.C.2.3.1.57 - mostly in animals) and Pao (E.C.1.5.3.11 - animals and plants). The predominant PAs that are often found in fungi are Put and Spd, while some fungal genera might lack Spm (reviewed in Valdés-Santiago et al., 2012). Given the requirement of PAs to maintain normal growth, development, and pathogenesis, the PA biosynthetic pathway (Figure 1) has often been a target to restrict fungal pathogenesis in both plants and animals (reviewed in Valdés-Santiago et al., 2012). In fungi, while Put is associated with hyphal growth, Spd has been implicated in cellular events associated with cell division, sporulation, and mycotoxin production. In the model fungus Aspergillus nidulans (A. nidulans), inactivation of spds altered fungal growth in the mutant (an auxotroph for Spd) and reduced sterigmatocystin production in vitro (Jin et al., 2002). In the human pathogenic fungus Penicillium marneffei ( $P$. marneffei), impairment of Spd biosynthesis in a samdc ( $\operatorname{sadA}$ ) mutant reduced growth, conidiogenesis, spore germination, and temperature-dependent dimorphic transition (Kummasook et al., 2013). Exogenous supply of Spd to the $P$. marneffei sadA mutant could restore the WT phenotype. In wheat, early activation of the PA biosynthetic pathway has been reported in response to Fusarium head blight and PA pathway intermediates have been correlated with the production of deoxynivalenol (DON; 




FIGURE 1 | Polyamine (PA) pathway. Overview of the PA biosynthetic pathway (modified from Majumdar et al., 2015) in connection with amino acids (AAs) and tricarboxylic (TCA) cycle metabolites in plants and fungi. Dashed arrows indicate multiple steps. Abbreviations of enzymes, with EC numbers: AL, argininosuccinate lyase (EC 4.3.2.1); arginase (EC 3.5.3.1); AS, argininosuccinate synthase (EC 6.3.4.5); ODC, ornithine decarboxylase (EC 4.1.1.17); OTC, ornithine transcarbamylase (EC 2.1.3.3); PAO, polyamine oxidase (EC 1.5.3.11); SAMDC, S-adenosylmethionine decarboxylase (EC 4.1.1.50); SPDS, spermidine synthase (EC 2.5.1.16); SPMS, spermine synthase (EC 2.5.1.22); SSAT, Spd/Spm $N^{1}$-acetyl-transferases (EC 2.3.1.57). Other abbreviations: dcSAM, decarboxylated S-adenosylmethionine; GABA, $\gamma$-aminobutyric acid; Glu, glutamate; OAA, oxaloacetic acid; P5C, $\Delta^{1}$-pyrroline-5-carboxylate; Pro, proline; Put, putrescine; SAM, S-adenosylmethionine; Spd, spermidine; Spm, spermine; TCA, tricarboxylic acid.

Gardiner et al., 2009, 2010). In fact, Put activated the production of DON by regulating the expression of its biosynthetic genes (Gardiner et al., 2009).

Polyamines are common to both plants and fungal pathogens, and their metabolism can play significant roles in host defense as well as successful pathogenesis and mycotoxin production during compatible host-pathogen interactions (Gardiner et al., 2009, 2010; Valdés-Santiago and Ruiz-Herrera, 2013; reviewed in Takahashi, 2016). It was demonstrated that the fungus Tapesia yallundae, rendered avirulent due to inactivation of the odc gene, had virulence restored upon re-introduction back into plants, possibly due to the uptake of PAs from the host thus compensating for PA depletion in the pathogen (Mueller et al., 2001). One of the important genes in higher PA biosynthesis is spds, whose product Spd, plays a critical role in mRNA translation due to its requirement for hypusination-mediated activation of eukaryotic translation initiation factor 5A (eIF5A) in all organisms, including fungi (Martinez-Rocha et al., 2016). The current study was undertaken to investigate if the A. flavus spds (AFLA_017920) gene could be a suitable target to reduce fungal pathogenesis during maize seed infection. Our results show that inactivation of spds in A. flavus significantly reduced fungal infection, sporulation and aflatoxin production in vitro and during maize seed infection.

\section{MATERIALS AND METHODS}

\section{Fungal Strains, Media, and Growth Conditions}

Aspergillus flavus CA14 ( $\Delta k u 70, \Delta p y r G, \Delta$ niaD) was used as host for transformation. Unless otherwise stated, CA14 pyrG-1, transformed with plasmid pPG2.8 (Cary et al., 2015) carrying the A. parasiticus pyrG gene was used as control for all experiments. A WT A. flavus 70 (AF70), capable of producing significantly higher levels of aflatoxins and sclerotia than CA14, was used to study the effect of PAs on SM and sclerotia production. A WT CA14 was used as the control for maize kernel infection studies. Fungal strains were cultured on Czapek-Dox (CZ) medium (Difco, BD). The medium was supplemented with Spd $(0.5$ or $0.25 \mathrm{mM})$ or Spm $(0.2$ or $0.1 \mathrm{mM})$ [both Spd and Spm were purchased from Sigma-Aldrich, St. Louis, MO, 
United States] as required. As CZ medium is not conducive for aflatoxin production, A\&M medium (Mateles and Adye, 1965) supplemented with Spd and Spm was used to study the effects of PAs on aflatoxin production. Solid media were prepared by adding 15 g. $\mathrm{L}^{-1}$ of agar. Fungal cultures were grown in light or dark at $30^{\circ} \mathrm{C}$.

For maize kernel inoculation studies, an aflatoxin-producing A. flavus CA14 WT strain was obtained from the SRRC fungal collection (SRRC 1436; USDA Agricultural Research Service, New Orleans, LA, United States). The fungal strain was grown on $\mathrm{CZ}$ agar medium for 7 days at $30^{\circ} \mathrm{C}$ with illumination. Conidia were harvested by flooding each plate with $20 \mathrm{ml}$ of $0.02 \%(\mathrm{v} / \mathrm{v})$ sterile Triton X-100 solution and gently dislodging conidia from the surface mycelia using a sterile scraper. Conidial suspensions were adjusted to $4 \times 10^{6}$ spores $/ \mathrm{ml}$ prior to inoculation of kernels.

\section{Generation of Deletion and Complementation spds Strains}

The spds (AFLA_017920) deletion cassette was constructed by fusion PCR as described by Szewczyk et al. (2006). The $5^{\prime}$ and $3^{\prime}$ regions flanking the spds gene were PCR amplified from $A$. flavus CA14 genomic DNA using primer sets Spds_5F/Spds_5R and Spds_3F/Spds_3R, respectively (Supplementary Table S1). The middle fragment containing the pyrG marker gene was PCR amplified from the cDNA of $A$. parasiticus (BN9 strain), using the primers pyrG_F and pyrG_R (Supplementary Table S1). The three PCR fragments were then fused together through PCR using the nested primer pair Spds_nest-F and Spds_nest-R. The final PCR product (3739 bp) was used for polyethylene glycol-mediated transformation of A. flavus CA14 protoplasts as described by Cary et al. (2006). A number of putative $\Delta s p d s$ transformants $(\Delta k u 70, \Delta$ niaD, pyrG+) were isolated and analyzed by PCR. Replacement of the spds coding region with pyrG selectable marker was confirmed through PCR using the primer pair $S p d s \_5 F$ and $p y r G \_R$ (Supplementary Figure S1). CA14 transformed with plasmid pPG2.8 (Cary et al., 2015) carrying the A. parasiticus pyrG gene was used as an isogenic control (referred to as the control).

To genetically complement the CA14 $\Delta s p d s$ mutant, the spds gene region including $615 \mathrm{bp}$ of the $5^{\prime}$ UTR and $286 \mathrm{bp}$ of the $3^{\prime}$ UTR was PCR amplified from WT CA14 gDNA using prom_F2 and term_R primers. The A. parasiticus (BN9 strain) pyrG selectable marker gene was PCR amplified using primer pair pyrG_F1 and pyrG_R1, and was fused to the $2.6 \mathrm{~kb} s p d s \mathrm{PCR}$ product through overlap fusion PCR using primer pairs prom_nest-F and pyrG_nest-R, that generated a $4.1 \mathrm{~kb}$ PCR product. The final PCR product (spds-pyrG, $4.1 \mathrm{~kb}$ ) was used for polyethylene glycol-mediated transformation of $\Delta s p d s$ CA14 ( $\Delta k u 70, \Delta n i a D, p y r G+)$ protoplasts. To select genetically complemented $\Delta s p d s$ transformants $\left(\Delta s p d s^{\mathrm{C}}, \Delta k u 70, \Delta\right.$ niaD, pyrG+), protoplasts (post-transformation) were plated onto regeneration medium (Cary et al., 2006) without Spd. Replacement of the $\Delta s p d s$ coding region with the spds-pyrG complementation PCR product was confirmed through PCR using the primer pair 017920prom_nest-F and pyrG_nest-R (Supplementary Figure S2). PCR amplifications for creating the $\Delta s p d s$ knockout construct were performed using ExTaq HS polymerase (Takara Bio, Inc., Mountain View, CA, United States), while the spds-pyrG complementation construct was generated using Phusion polymerase (New England BioLabs, Ipswich, MA, United States). The primers used in construction of the knockout mutant and complementation strain are listed in Supplementary Table S1.

\section{Nucleic Acid Isolation and Analysis}

Fungal genomic DNA was extracted from mycelia following $24 \mathrm{~h}$ incubation with shaking $(250 \mathrm{rpm})$ at $30^{\circ} \mathrm{C}$ in $\mathrm{CZ}$ broth using a MasterPure Yeast DNA Purification Kit (Epicentre, Madison, WI, United States) according to the manufacturer's instructions. To confirm the successful integration of either knockout or complementation gene cassettes, genomic DNA isolated from transformants was PCR amplified using ExTaq HS polymerase and specific primer pairs listed in Supplementary Table S1.

\section{Morphological Analysis}

Conidia $\left(10^{6}\right.$ spores $\left./ \mathrm{ml}\right)$ of the CA14 control and $\Delta$ spds mutant strains were used to inoculate $\mathrm{CZ}$ agar plates with or without Spd supplementation and grown under illumination at $30^{\circ} \mathrm{C}$. Sixmillimeter diameter cores were collected from the center of each colony (from three replicate plates) at 5 days post-inoculation (dpi). The cores were homogenized, and conidia were counted using a Hemocytometer (Hausser Scientific, Horsham, PA, United States) and a Leitz Laborlux S bright-field microscope (Leica Microsystems, Inc., Buffalo Grove, IL, United States).

The AF70 strain was used to study the effects of PAs on sclerotia and SM production. Conidia $\left(10^{6}\right.$ spores $\left./ \mathrm{ml}\right)$ of AF70 were point inoculated $(2 \mu \mathrm{l})$ at the center of $\mathrm{CZ}$ agar plates supplemented with Spd $(0.25$ and $0.50 \mathrm{mM})$ or Spm (0.1 and $0.2 \mathrm{mM}$ ) along with control plates ( $\mathrm{CZ}$ only) in duplicate. The culture plates were grown in the dark at $30^{\circ} \mathrm{C}$. After 14 days, sclerotia were counted using a Leitz Laborlux S bright-field microscope under $10 \times$ optical lens. Plate images were captured using a PowerShot SD790 IS camera (Canon USA Inc., Melville, NY, United States).

\section{Maize Kernel Inoculation and Incubation}

Undamaged and roughly uniform sized maize (Zea mays var. B73) kernels were randomly assigned and processed according to a kernel screening assay (KSA; Rajasekaran et al., 2013). All kernels were surface sterilized using 70\% ethanol, air dried, and stored under sterile conditions. Kernels were inoculated by immersion into a suspension of $4 \times 10^{6}$ spores $/ \mathrm{ml}$ of the CA14 WT (grown on CZ agar medium), CA14 WT w/Spd (CZ agar medium $+0.5 \mathrm{mM} \mathrm{Spd}$ ), and $\Delta s p d s \mathrm{w} / \mathrm{Spd}$ (CZ agar medium with ammonium sulfate $+0.5 \mathrm{mM} \mathrm{Spd}$ ) strains followed by stirring for $3 \mathrm{~min}$. Following removal of excess inoculum, the kernels were transferred to plastic caps that were placed in trays with a sheet of $3 \mathrm{MM}$ paper on the bottom. The paper was saturated with sterile $\mathrm{ddH}_{2} \mathrm{O}$ and the tray covered with a lid. The kernels were incubated under high $\mathrm{RH}(>90 \%)$ at $31^{\circ} \mathrm{C}$ in the dark for 8 days. The filter papers inside the trays were kept 
moist by adding sterile water when needed during this incubation period.

\section{Quantification of Polyamines and Amino Acids}

Freeze dried mycelia were subjected to three cycles of freezing $\left(-20^{\circ} \mathrm{C}\right)$ and thawing (room temperature) in 5\% PCA. After the final thaw, samples were vortexed for $2 \mathrm{~min}$ and centrifuged for $8 \mathrm{~min}$ at $14,000 \times \mathrm{g}$. PAs and AAs were simultaneously dansylated and quantified using an HPLC method from Minocha and Long (2004) with following modifications. Samples were incubated at $60^{\circ} \mathrm{C}$ for $30 \mathrm{~min}$, cooled for $3 \mathrm{~min}$ and then microfuged at $14,000 \times g$ for $30 \mathrm{~s}$. The reaction was terminated by the addition of $45 \mu \mathrm{l}$ of glacial acetic acid. Sample tubes were kept open for $3 \mathrm{~min}$ under a flow hood to allow $\mathrm{CO}_{2}$ bubbles to escape. Acetone used to dissolve dansyl chloride was evaporated using a SpeedVac Evaporator (Savant, Farmingdale, NY, United States) for $5 \mathrm{~min}$. Finally, $1735 \mu \mathrm{l}$ of filtered HPLC grade methanol was added to all tubes bringing the total volume to $2 \mathrm{ml}$. PAs and AAs were analyzed by HPLC method according to Minocha and Long (2004). The data were processed using Perkin Elmer TotalChrom software (version 6.2.1).

\section{Secondary Metabolite Analysis}

Maize kernels ( 20-70 mg) inoculated with WT CA14 and $\Delta s p d s$ mutant strains were homogenized and extracted in $1 \mathrm{ml}$ of ethyl acetate/acetone (1:1)/0.1\% formic acid solution at room temperature for $24 \mathrm{~h}$. The extracts were filtered through cotton plugs and the filtrates were concentrated under $\mathrm{N}$ to dryness. Each extract was re-dissolved in acetonitrile $(1 \mathrm{mg} / \mathrm{ml})$, filtered through a $0.22 \mu \mathrm{m}$ Spin-X centrifuge tube filter, and analyzed using a Waters ACQUITY UPLC system (40\% methanol in water, $\mathrm{BEH} \mathrm{C} 181.7 \mu \mathrm{m}, 2.1 \mathrm{~mm} \times 50 \mathrm{~mm}$ column) using fluorescence detection $(\mathrm{Ex}=365 \mathrm{~nm}, \mathrm{Em}=440 \mathrm{~nm})$. Samples were diluted to 10 -fold if the aflatoxin signal saturated the detector. Analytical standards (Sigma-Aldrich, St. Louis, $\mathrm{MO}$, United States) were used to identify and quantify aflatoxins: aflatoxin B1 (AFB1); aflatoxin B2 (AFB2). Aflatoxin content was expressed in $\mathrm{ng} / \mathrm{mg}$ fresh weight of homogenized kernels.

For analysis of other SMs, AF70 was grown on CZ agar with ammonium sulfate (supplemented with Spd at 0.5 and $0.25 \mathrm{mM}$ or Spm at 0.2 and $0.1 \mathrm{mM}$ ) medium at $30^{\circ} \mathrm{C}$ in the dark for 14 days along with controls with no PAs. Fungal cultures were lyophilized and then extracted with ethyl acetate $/ 0.1 \%$ formic acid for $24 \mathrm{~h}$ at room temperature $(2 \times)$. These extracts were concentrated in vacuo. The dried extracts were re-dissolved in methanol at $5 \mathrm{mg} / \mathrm{ml}$ and filtered for analysis on the Waters ACQUITY UPLC system using PDA UV and QDA mass detection using the following conditions: $0.5 \mathrm{ml} / \mathrm{min}$, solvent A $(0.1 \%$ formic acid in water); solvent B $(0.1 \%$ formic acid in acetonitrile); $5 \% \mathrm{~B}(0-1.25 \mathrm{~min})$, gradient to $25 \% \mathrm{~B}$ (1.25-1.5 min), gradient to $100 \%$ B $(1.5-5.0 \mathrm{~min}), 100 \% \mathrm{~B}$ (5.0-7.5 min), then column equilibration 5\% B (7.6-10.1 min). Peaks were identified using authentic standards. Cyclopiazonic acid (CPA) was purchased from Sigma-Aldrich (St. Louis, MO, United States). Aflavinine and aflatrem standards were kind gifts from Dr. James Gloer, University of Iowa, Iowa City, IA, United States.

\section{RNA Isolation, cDNA Synthesis, and Gene Expression Analysis}

Total RNA was isolated from homogenized A. flavus-infected maize kernels using 'Spectrum ${ }^{\mathrm{TM}}$ Plant Total RNA kit' (SigmaAldrich, St. Louis, MO, United States) and cDNA was synthesized using iScript ${ }^{\mathrm{TM}}$ cDNA synthesis kit (Bio-Rad, Hercules, CA, United States) according to the manufacturer's protocols. The ZR Fungal/Bacterial RNA MiniPrep ${ }^{\text {TM }}$ kit (Zymo Research, Irvine, CA, United States) was used for RNA extraction from A. flavus mycelial samples. Quantitative RT-PCR (qRT-PCR) was performed using SYBR green I chemistry and iCycler iQ5 Multicolor real-time PCR detection system (Bio-Rad). The thermocycler conditions included a pre-incubation at $95^{\circ} \mathrm{C}$ for $3 \mathrm{~min}$, dye activation at $95^{\circ} \mathrm{C}$ for $10 \mathrm{~s}$, primer annealing at $55^{\circ} \mathrm{C}$ for $30 \mathrm{~s}$, elongation at $55^{\circ} \mathrm{C}$ for $50 \mathrm{~s}$ followed by a dissociation curve from 65 to $95^{\circ} \mathrm{C}$ for $30 \mathrm{~min}$ (with $0.5^{\circ} \mathrm{C}$ increments). The primers used for qRT-PCR are shown in Supplementary Table S2. Gene expression was normalized by $\Delta \Delta C_{\mathrm{T}}$ analysis (Livak and Schmittgen, 2001) to A. flavus $\beta$-tubulin gene (AFLA_068620) or Zea mays ribosomal structural gene GRMZM2G024838 expression (Shu et al., 2015) utilizing the gene expression analysis software package of the Bio-Rad iQ5.

Determination of fungal load in the maize kernels infected with the WT and $\Delta s p d s$ A. flavus CA14 strains were performed on 8 dpi samples. Fungal load was measured (using a method similar to that of Thakare et al. (2017) as relative expression of A. flavus $\beta$-tubulin gene (AFLA_068620) to the maize ribosomal structural gene GRMZM2G024838 (Shu et al., 2015).

\section{Statistical Analysis}

Statistical significance between control and treatments were determined by Student's $t$-test. Significant difference between control and treatment were analyzed at ${ }^{* *} P \leq 0.05$ and/or ${ }^{*} P \leq 0.10$ as indicated in the legends of Figures and Table.

\section{RESULTS}

\section{Phenotypic Analyses of $A$. flavus $\Delta s p d s$ Mutant and Genetic Complementation of the Mutant}

Disruption of the spds gene in the A. flavus CA14 strain was confirmed by PCR analysis, and a single representative knockout strain was selected for subsequent analyses (Supplementary Figure S1). Loss of spds gene expression in the selected knockout was confirmed by qRT-PCR (Supplementary Figure S1). Inactivation of A. flavus spds resulted in a total loss of growth and sporulation in the $\Delta s p d s$ mutant as compared to the CA14 pyrG-1 control in the absence of exogenously supplied Spd in the $\mathrm{CZ}$ growth medium (Figures 2A,B). Addition of $0.5 \mathrm{mM} \mathrm{Spd}$ 


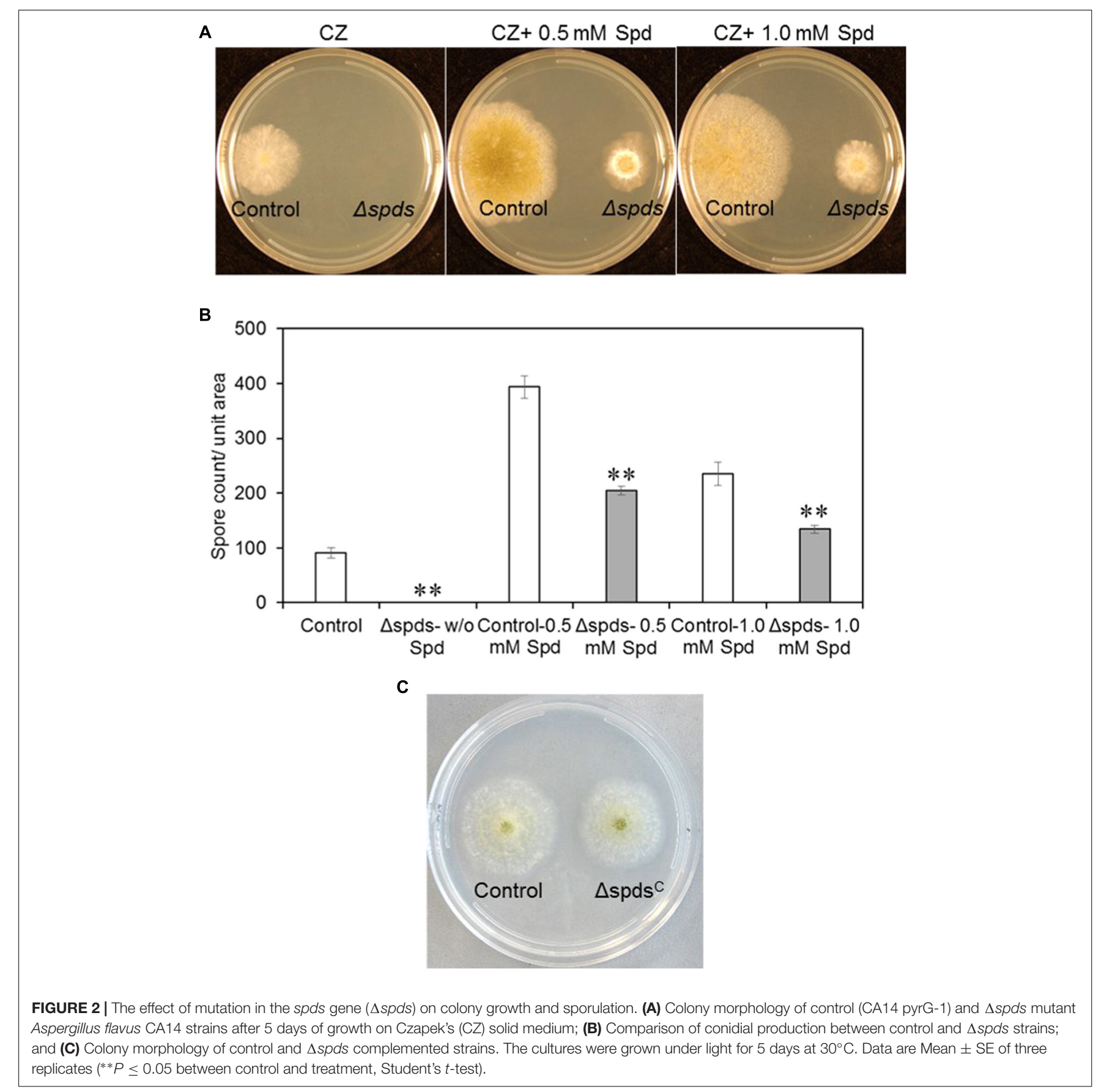

restored sporulation in the $\Delta s p d s$ mutant but it was still $<50 \%$ of that observed in the control grown in $0.5 \mathrm{mM}$ Spd. An increase of Spd concentration in the CZ medium to $1.0 \mathrm{mM}$ from $0.5 \mathrm{mM}$ reduced sporulation by $34 \%$ in the $\Delta s p d s$ mutant. A significant increase (334\%) in spore production was observed in the control strain in response to $0.5 \mathrm{mM}$ Spd compared to the $\Delta s p d s$ mutant that was $49 \%$ less than the control at this concentration. An increase in Spd concentration to $1.0 \mathrm{mM}$ had less promotional effect than $0.5 \mathrm{mM}$ Spd on spore production in the control strain. Genetic complementation of the $\Delta s p d s$ mutant $\left(\Delta s p d s^{C}\right)$ with a WT A. flavus spds gene restored host strain levels of sporulation and aflatoxin production without any exogenous supply of Spd (Figure 2C and Supplementary Figures S2, S3).

\section{Polyamine Content}

Among the three different PAs analyzed (Figure 3A) in A. flavus mycelia, the concentration of Spd was highest $(1.730 \mu \mathrm{M} / \mathrm{mg}$ DW), followed by Put $(0.4 \mu \mathrm{M} / \mathrm{mg} \mathrm{DW})$ and Spm $(0.1 \mu \mathrm{M} / \mathrm{mg}$ DW) in the control strain (CA14 pyrG-1) at 8 dpi when grown in $\mathrm{CZ}$ liquid medium. Addition of $0.5 \mathrm{mM}$ Spd in the growth medium significantly decreased Put content by $134 \%$, whereas cellular contents of Spd increased by $108 \%$ in the control. 

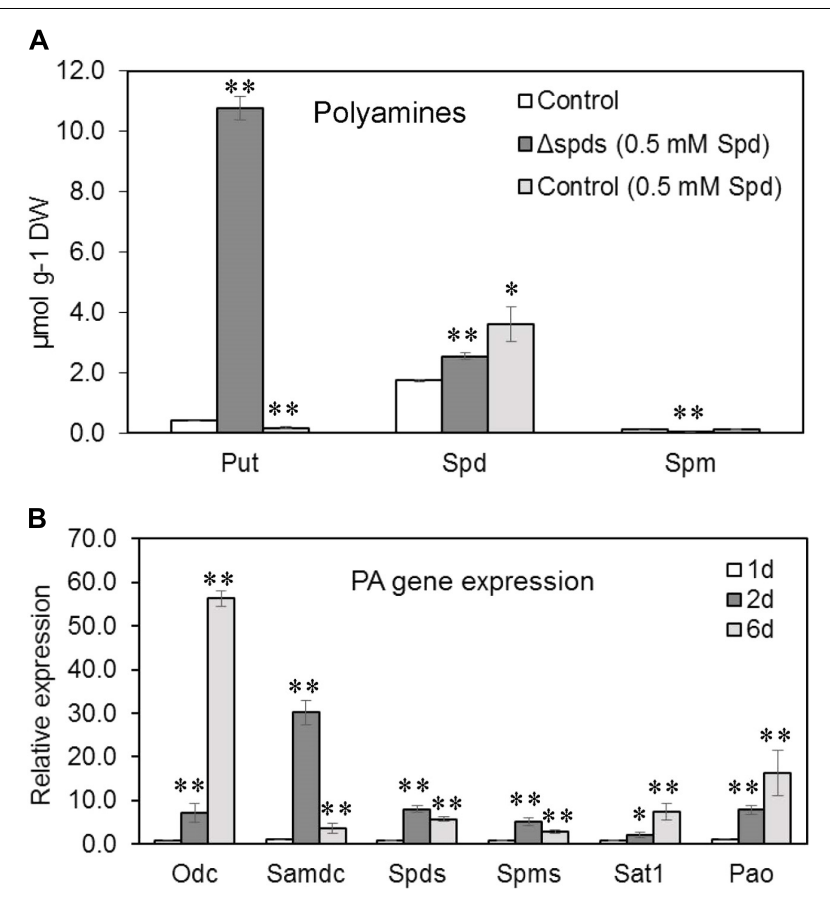

FIGURE 3 | Polyamine contents and PA gene expression. (A) PA contents in the control (CA14 pyrG-1) and $\Delta$ spds A. flavus CA14 strains grown in

Czapek's liquid medium (shake culture) with or without spermidine (Spd) for 8 days in the dark at $30^{\circ} \mathrm{C}$; and (B) Developmental expression of PA genes (odc, samdc, spds, spms, sat1, pao) in A. flavus control strain (CA14 pyrG-1) grown in Czapek's liquid medium (static culture) for 6 days in the dark at $30^{\circ} \mathrm{C}$. Data are Mean \pm SE of three replicates $\left({ }^{*} P \leq 0.05\right.$ and ${ }^{*} P \leq 0.10$ between control and treatment or in comparison to day 1 in $\mathbf{B}$, Student's $t$-test).

Whereas, in the $\Delta s p d s$ mutant (supplemented with $0.5 \mathrm{mM} \mathrm{Spd}$ ), cellular content of Put and Spd increased by 2619 and 52\%, respectively, and Spm decreased by $2042 \%$ as compared to the control.

\section{Expression of Polyamine Biosynthetic Genes in A. flavus During Development}

The expression of all PA biosynthetic genes (odc, samdc, spds, and spms) and PA back conversion genes (pao, sat 1) studied increased by several fold from day 1 to day 2 during early developmental stages in the control strain (CA14 pyrG-1; Figure 3B). The change in expression of the samdc gene was the highest (31-fold) followed by spds (10-fold), odc (8-fold), spms and pao (6-fold), and sat 1 (3-fold). At day 6, the expression of samdc, spds, and spms were lower than their corresponding expression values at day 2 while $o d c$, pao, and sat 1 were up-regulated by 60-, 14-, and 9 -fold, respectively, from their corresponding values at day 1 .

\section{Amino Acids Analyses}

The PA biosynthetic pathway is intimately associated with AA metabolism, therefore cellular AAs content was analyzed in the $\Delta s p d s$ mutant along with the control (CA14 pyrG-1) A. flavus strains. Among the different PCA soluble AAs that were resolved by our HPLC method (Table 1), cellular content (\% of the total soluble AAs) of Arg + Thr constituted the highest (30\%) followed by Ala (16\%), Orn (11\%), and Lys (10\%). Among the remaining AAs whose cellular content was between $\geq 10 \%$ were GABA (9\%), Asp and Glu (7\% each), Ser and Gly (3\% each), and Pro (2\%). The AAs that were $<1 \%$ included Val, Ile, Leu, and Cys.

In general, the AAs whose cellular content (nmol/g DW basis) decreased significantly in the $\Delta s p d s$ mutant (vs. control) were Asp (42\%), Glu (33\%), Ser (22\%), Lys (17\%), and Cys (not detected in the $\Delta s p d s$ mutant). The AAs that increased significantly in the $\Delta s p d s$ mutant with Spd (vs. control) were Ala (16\%) and His (not detected in any other treatments). The AAs that were changed in the control with $0.5 \mathrm{mM}$ Spd vs. control (no Spd) were, Ala (36\% decrease) and Orn (40\% decrease).

\section{Effect of Exogenous Supply of Spd and Spm on Sclerotia Production}

To investigate if PAs promoted sclerotial production, $\mathrm{CZ}$ medium supplemented with PAs was used to inoculate the A. flavus AF70 strain (a high sclerotia-producing strain). Exogenous supply of PAs significantly increased the number of sclerotia and the percentage of mature (melanised) sclerotia when the AF70 strain was grown on CZ medium supplemented with Spd or Spm (Figures 4A,B). Supplementing CZ medium with 0.25 or $0.5 \mathrm{mM}$ of Spd increased the total number of sclerotia by 32 and $47 \%$, respectively, as compared to the non-supplemented control (Figure 4B). The effect of Spd was more pronounced on the production of mature sclerotia resulting in a 61 and $57 \%$ increase with 0.25 and $0.5 \mathrm{mM} \mathrm{Spd}$, respectively (vs. non-supplemented control). Supplementation of CZ medium with Spm significantly increased the number of mature sclerotia by $24 \%$ at $0.2 \mathrm{mM}$. No significant changes in sclerotia production were observed at any other concentration of Spm used.

\section{Effect of Exogenous Supply of Spd and Spm on Secondary Metabolites Production, and Associated Gene Expression in A. flavus}

Aspergillus flavus 70, a producer of high levels of aflatoxins and sclerotia, was used to study the effects of PAs on SM production. UPLC-MS analysis of AF70 extracts grown on CZ medium (with ammonium sulfate) in the presence of Spd showed an overall significant increase in the production of SMs compared to the control (untreated) or Spm treated samples. Indole diterpenes, particularly aflavinines $(1,3,6$; Figure $\mathbf{5 A})$ and aflatrems (4, 5; Figure 5A), and CPA (2; Figure 5A) were significantly increased when Spd was added to the culture medium. Spermine also significantly increased the production of aflavinines, aflatrems, and CPA that varied with the Spm concentration. The overall effect of Spd on the production of aflavinines and aflatrems was higher than Spm. CZ medium is not conducive for the production of aflatoxins, therefore, A\&M medium, which contains ammonium sulfate and supports aflatoxin biosynthesis was used to study the effects of PAs on aflatoxin production. Spermine (as compared to Spd) had a greater impact on the production of aflatoxins. At 0.1 and $0.2 \mathrm{mM}$ Spm there was a significant increase in AFB1 content of 44 and 


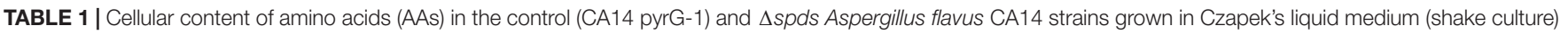
with or without exogenous spermidine (Spd).

\begin{tabular}{|c|c|c|c|}
\hline Treatment & Control (nmol/g dry wt) & $\Delta s p d s(0.5 \mathrm{mM} \mathrm{Spd})(\mathrm{nmol} / \mathrm{g}$ dry wt) & Control (0.5 mM Spd) (nmol/g dry wt) \\
\hline Glu & $4712.40 \pm 428.94$ & $3163.80 \pm 219.81^{* *}$ & $2987.40 \pm 666.34$ \\
\hline Orn & $7421.20 \pm 465.23$ & $7159.47 \pm 491.46$ & $4428.33 \pm 861.85^{*}$ \\
\hline Pro & $1103.80 \pm 73.81$ & $1186.07 \pm 16.98$ & $840.33 \pm 150.36$ \\
\hline His & nd & $1240.40 \pm 114.74^{* *}$ & nd \\
\hline Arg+Thr & $19818.07 \pm 945.68$ & $13079.27 \pm 4183.29$ & $16423.47 \pm 2522.16$ \\
\hline GABA & $5995.93 \pm 257.44$ & $5757.93 \pm 88.34$ & $5858.00 \pm 1159.22$ \\
\hline Ser & $2125.80 \pm 140.12$ & $1651.00 \pm 93.44^{*}$ & $1848.53 \pm 270.65$ \\
\hline Gly & $1859.33 \pm 150.76$ & $1491.27 \pm 56.75$ & $1367.27 \pm 239.29$ \\
\hline Cys & $85.40 \pm 4.77$ & $n d^{* *}$ & $23.13 \pm 23.13$ \\
\hline Lys & $6284.72 \pm 253.33$ & $5185.80 \pm 329.61^{*}$ & $4241.67 \pm 892.49$ \\
\hline Ala & $10516.67 \pm 453.23$ & $12194.40 \pm 339.64^{* *}$ & $6727.73 \pm 1135.51^{*}$ \\
\hline Asp & $4822.07 \pm 386.00$ & $2799.07 \pm 304.30^{* *}$ & $2858.40 \pm 758.38$ \\
\hline Val & $596.40 \pm 14.62$ & $597.20 \pm 18.45$ & $604.20 \pm 114.76$ \\
\hline Ile & $429.20 \pm 4.72$ & $424.33 \pm 6.90$ & $385.33 \pm 81.91$ \\
\hline Leu & $425.90 \pm 15.50$ & $370.53 \pm 20.16$ & $463.13 \pm 94.44$ \\
\hline
\end{tabular}

The cultures were grown in the dark for 8 days at $30^{\circ} \mathrm{C}$. Data are Mean $\pm S E$ of three replicates (**P $\leq 0.05$ and ${ }^{*} P \leq 0.10$ between wild type $(W T)$ and treatment, Student's t-test); nd, not detected; Glu, glutamate; Orn, ornithine; Pro, proline; His, histidine; Arg+Thr, arginine+threonine; GABA, $\gamma$-aminobutyric acid; Ser, serine; Gly, glycine; Cys, cysteine; Lys, lysine; Ala, alanine; Asp, aspartate; Val, valine; lle, isoleucine; Leu, leucine.

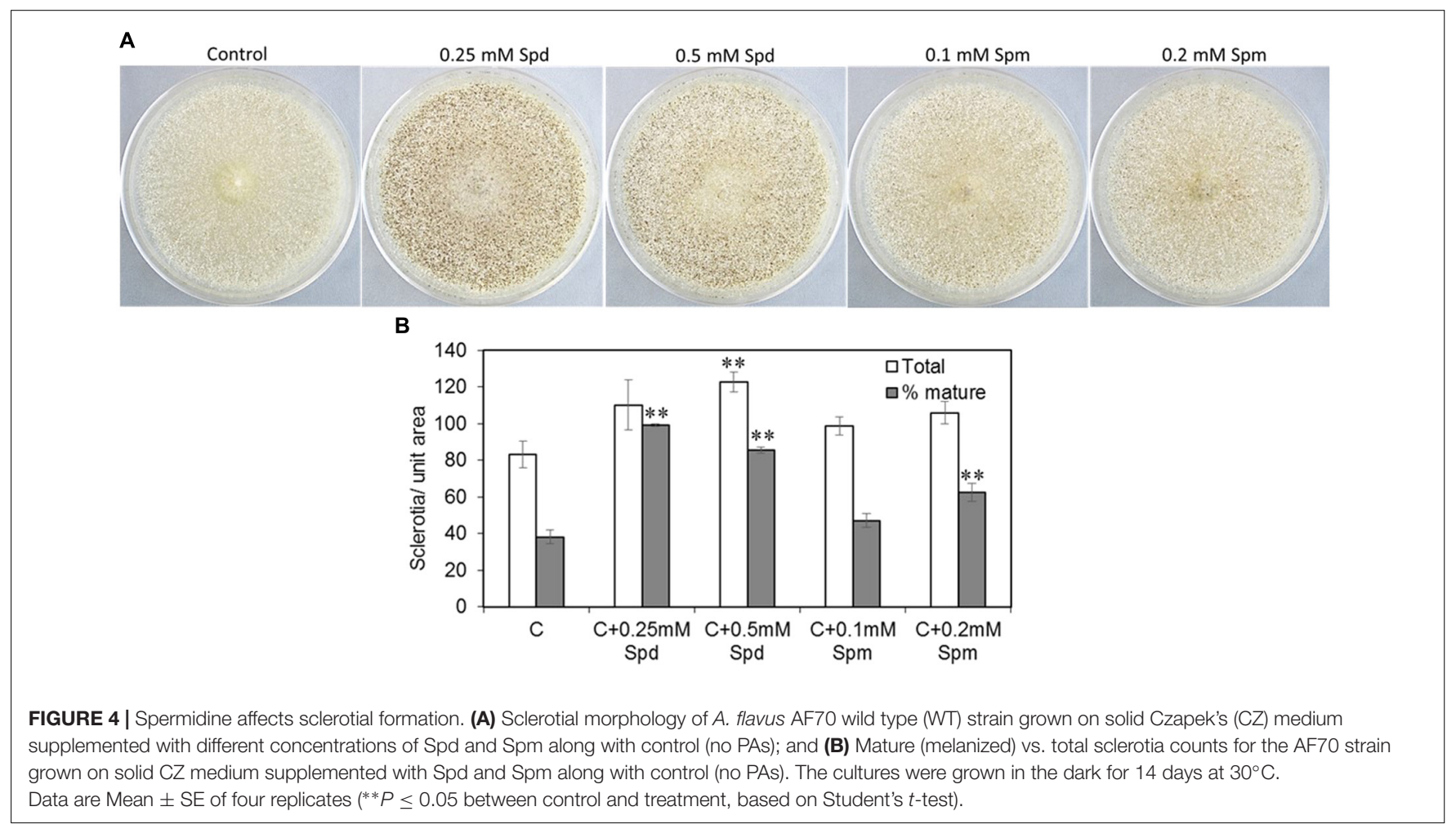

92\%, respectively (vs. control; Figure 5B), and AFB2 content by 52 and $135 \%$, respectively (vs. control). Spd on the other hand, at $0.25 \mathrm{mM}$ increased AFB1 and AFB2 content by 17 and $28 \%$, respectively, and decreased AFB2 by $14 \%$ at without any significant change in AFB1 at $0.5 \mathrm{mM}$ concentration (vs. control; Figure 5B).

As PAs in general, significantly increased SM production, we wanted to determine if this was due to up-regulation of
SM pathway-specific and global regulatory genes. Expression of biosynthetic genes associated with production of aflavinine and aflatrem (atmC; AFLA_096390 and atmM; AFLA_096400), CPA (cpaA; AFLA_139490) as well as the global regulators of secondary metabolism, nsdC (AFLA_131330), laeA (AFLA_033290), and veA (AFLA_066460) was determined following 5 days growth of AF70 in CZ broth supplemented with Spd or Spm. The expression of atmM and $a t m C$ were both 
A
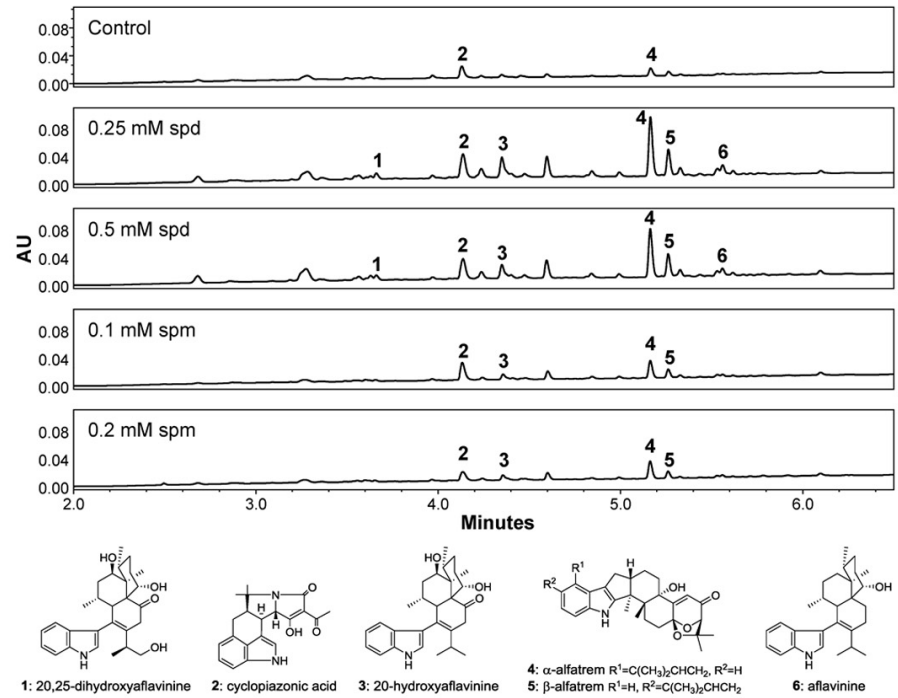

4: $\alpha$-alfatrem $\mathrm{R}^{1}-\mathrm{C}(\mathrm{CH}) \mathrm{CH}^{2} \mathrm{CH}_{2} \mathrm{R}^{2}=$

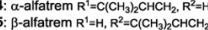
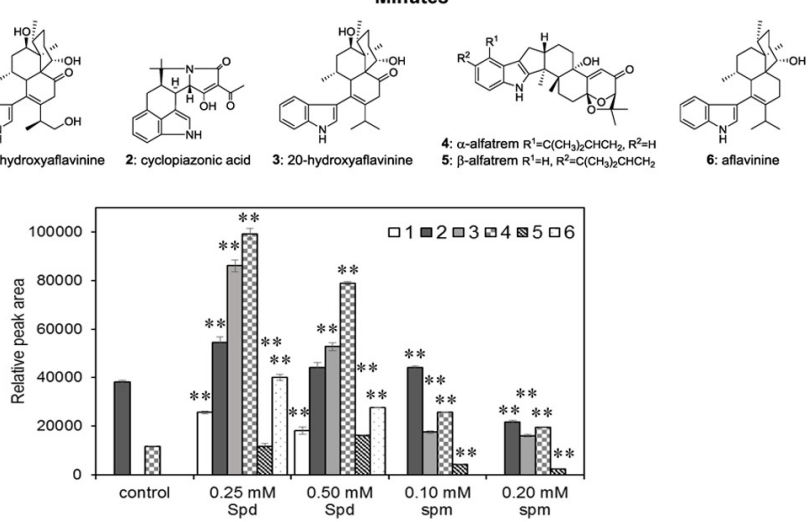

B

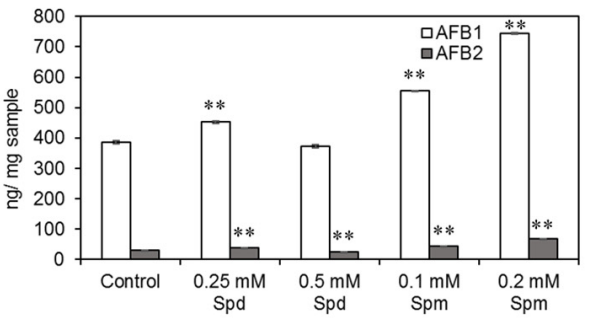

C

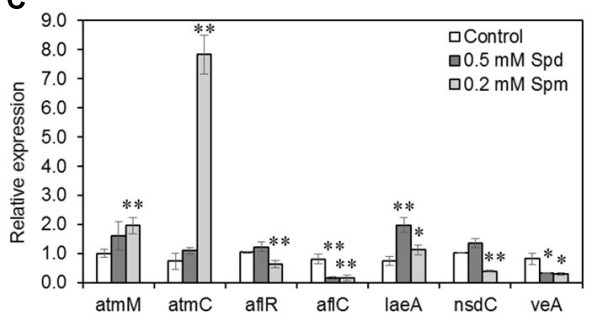

FIGURE 5 | The effects of Spermidine and Spermine (Spm) on secondary metabolite (SM) production and related gene expression. (A) Production of indole diterpene SMs (chromatograms at $\lambda=254 \mathrm{~nm}$ ) in A. flavus AF70 WT strain grown on solid Czapek's medium (with ammonium sulfate) supplemented with different concentrations of Spd and spermine along with control (no PAs) grown for 14 days in the dark at $30^{\circ} \mathrm{C}$. Aflatoxins were not detected in any of these samples as Czapek's medium is not conducive for aflatoxin production; (B) Production of aflatoxins in A. flavus AF70 WT strain grown on solid A\&M medium supplemented with different concentrations of Spd and spermine along with control (no PAs) grown for 7 days in the dark at $30^{\circ} \mathrm{C}$; (C) Effect of exogenous supply of Spd and Spm on the expression of secondary metabolite related genes, atmM, atmC, aflR, aflC, cpaA, and global regulatory genes, laeA, nsdC, and veA in $A$. flavus AF70 WT strain. The samples were grown in $\mathrm{CZ}$ liquid medium (static culture) for 5 days in the dark at $30^{\circ} \mathrm{C}$. Data are Mean $\pm \mathrm{SE}$ of three replicates $\left(^{* *} P \leq 0.05\right.$ and $* P \leq 0.10$ between control and treatment, Student's $t$-test).

up-regulated by Spm (Figure 5C), especially atm $C$ up-regulated (10.7-fold) by $0.2 \mathrm{mM}$ Spm compared to the control or Spd treated sample. Expression of laeA was increased by 2.6-fold in $0.5 \mathrm{mM}$ Spd with a small but significant increase in response to Spm. Spermine $(0.2 \mathrm{mM})$ down-regulated the expression of $v e A$ and $n s d C$ by 2 - to 3 -fold whereas a small increase in the expression of $n s d C$ and decrease in $v e A$ expression was observed by $0.5 \mathrm{mM}$ Spd. No significant change in the expression of $c p a A$ was observed in response to Spd or Spm treatments at 5 days of growth.

\section{Analysis of Fungal Growth and Aflatoxin Production in Infected Maize Kernels}

A maize seed infection assay using A. flavus WT CA14 and $\Delta s p d s$ was performed to investigate if $s p d s$ plays a role in pathogenicity and aflatoxin production during seed colonization. The $\Delta s p d s$ mutant (a Spd auxotroph) was grown on CZ medium supplemented with ammonium sulfate and $0.5 \mathrm{mM} \mathrm{Spd}$ for 8 days along with WT grown on CZ medium (with or without $0.5 \mathrm{mM}$
Spd) for the same time period prior to the harvest of spores for maize seed inoculation. In general, seeds infected with the WT strain (with or without Spd treatment) highly sporulated on the seed surface as opposed to the $\Delta s p d s$ mutant strain that produced less spores (Figure 6A). Estimation of fungal load within the seeds showed a 140 to 144 -fold higher growth in the WT $A$. flavus infected seeds as compared to $\Delta s p d s$ mutant infected seeds (Figure 6B).

Aflatoxin analysis of maize seeds infected with WT A. flavus (with or without Spd) produced significantly higher amounts of aflatoxins (18-30 ng/mg FW AFB1 and 0.8-1.0 ng/mg FW AFB2; Figures $7 \mathbf{A}, \mathbf{B})$ than the $\Delta s p d s$ infected seeds $(7.74 \mathrm{ng} / \mathrm{mg} \mathrm{FW}$ AFB1 and $0.26 \mathrm{ng} / \mathrm{mg}$ FW AFB2, respectively; Figures 7A,B).

\section{Expression Analyses of Aflatoxin and Polyamine Metabolism and Transport Genes in A. flavus and Maize}

During maize seed infection, the expression of putative PA transporter and pao genes was generally higher in 

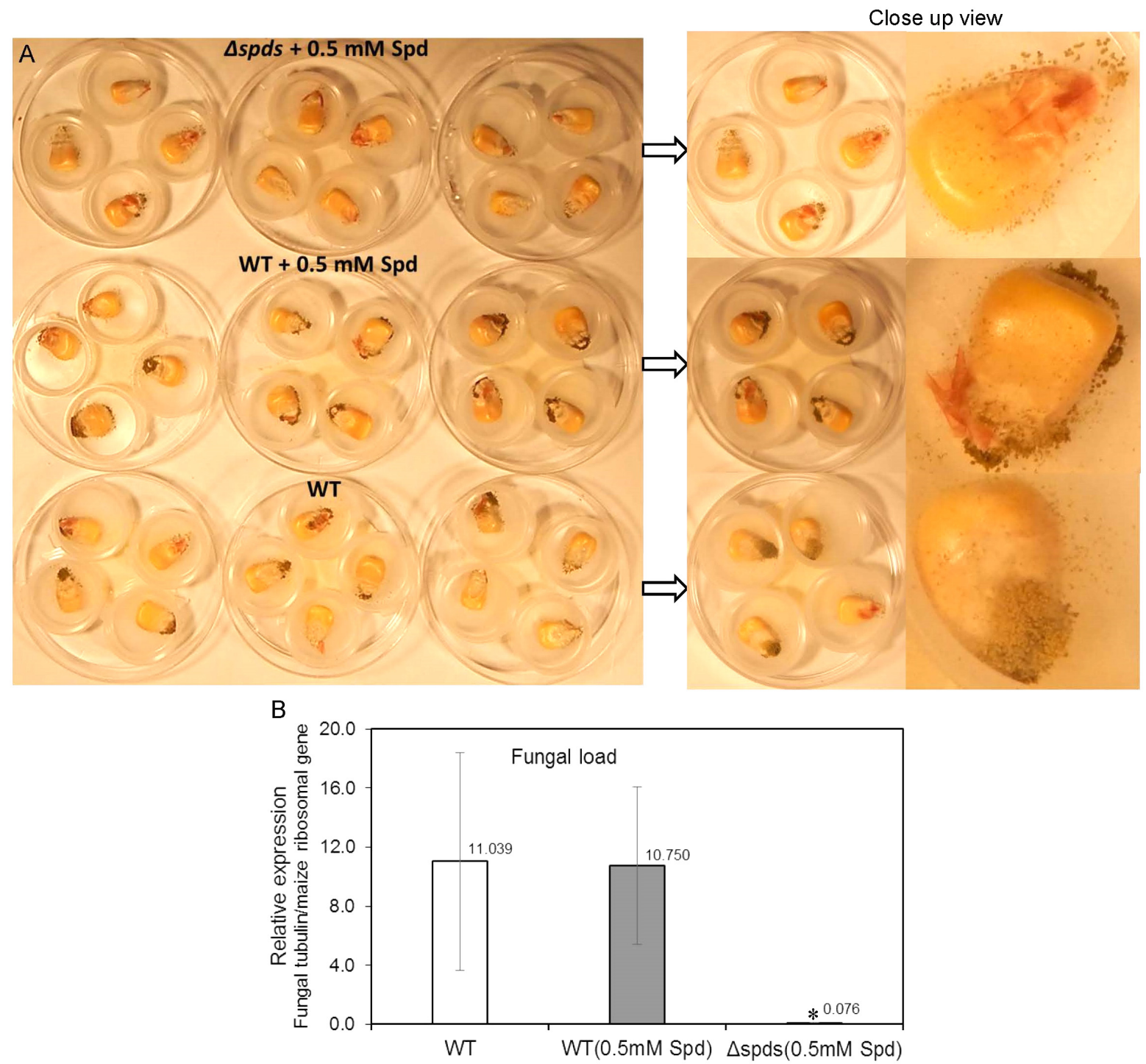

FIGURE 6 | The CA14 $\Delta$ spds mutant showing reduced pathogenicity during maize-A. flavus interaction. (A) Maize kernels at 8 days post-inoculation (dpi) were infected with either the CA14 WT or the $\Delta$ spds mutant (post-growth on CZ solid medium, which may or may not have been supplemented with Spd, for 1 week prior to the kernel inoculation); (B) Estimation of fungal load in maize kernels at 8 dpi, infected with WT and $\Delta$ spds CA14 strains. Fungal load was expressed as relative expression of the $\beta$-tubulin gene (AFLA_068620) to the maize ribosomal structural gene (used as housekeeping) GRMZM2G024838 (Shu et al., 2015). Data are Mean \pm SE of 3-4 replicates, each replicate consists of $4-5$ seeds; ( $P \leq 0.10$ between WT and treatment, Student's $t$-test).

the WT A. flavus strain (control) in comparison to the expression of other PA biosynthetic genes (Figure 8A). Among the different putative PA uptake transporters (dur3, AFLA_029660; $p a, \quad$ AFLA_024200; gap1, AFLA_073560; and agp2, AFLA_113740) that were identified as yeast orthologs in A. flavus, expression of dur3 was up-regulated (statistically significant) by 1.7 -fold in the WT vs. $\Delta s p d s$ mutant strain. Among the PA biosynthetic genes, expression of odc (AFLA_011800) and pao (AFLA_118340) was downregulated by 2 - and 3 -fold, respectively, in the $\Delta s p d s$ mutant compared to WT. Expression of samdc (AFLA_006490) gene was 2-fold higher in the $\Delta s p d s$ mutant and WT (0.5 mM Spd) vs. WT.
Different genes of the maize PA biosynthetic pathway as well as PA catabolism were analyzed to see if expression of genes associated with PA metabolism in the seeds respond differently when subjected to WT (virulent) vs. $\Delta s p d s$ mutant (less virulent) strains (Figure 8B). It is known that maize has multiple copies each of PA metabolism gene (Supplementary Table S2). Overall, the expression of ZmSamdc genes were highest followed by $Z m A d c$ genes as compared to the other PA genes. Expression of $\mathrm{ZmOdc}$ genes, $\mathrm{ZmOdc2}$ (XM_008672579) and ZmOdc3 (XM_008654778) did not vary much between samples and no expression of $Z m O d c 1$ (NM_001148682) was detected in any of the samples. Among the different $Z m A d c$ genes studied here, expression of both ZmAdc2 (NM_001138726) and ZmAdc3 


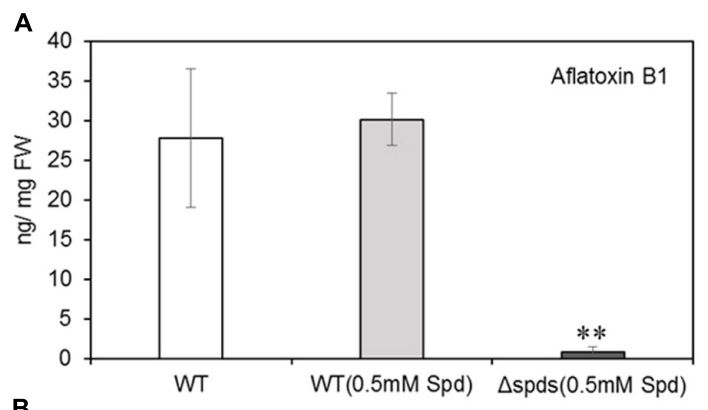

B

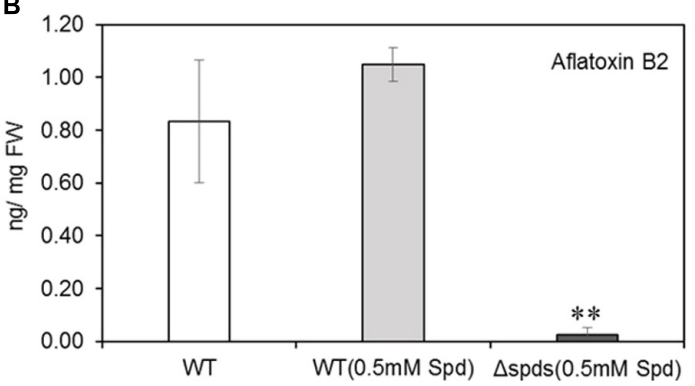

FIGURE 7 | Aflatoxin contents in maize kernels infected with WT and $\Delta$ spds A. flavus CA14 strains. (A) Aflatoxin B1; and (B) Aflatoxin B2.

Data are Mean \pm SE of four replicates, each replicate consists of 4-5 seeds (**P $\leq 0.05$ between WT and treatment, Student's $t$-test).

(XM_023300699) genes were up-regulated in the seeds infected with the WT strain only (vs. $\Delta s p d s$ mutant) with no expression of the ZmAdc4 (XM_008671538) gene in any of the samples. Expression of $\mathrm{ZmSamdc3}$ and $\mathrm{ZmSamdc4}$ were significantly high ( $>10$-fold higher than other genes) and were up-regulated in the seeds infected with the WT strain (vs. $\Delta s p d s$ mutant strain). Expression of ZmSpds3 (NM_001155814) and ZmSpms1 (NM_001112372) were higher in the seeds infected with the WT strain vs. $\Delta s p d s$ mutant strain. Among the six ZmPao genes, expression of ZmPao1 (NM_001111636) was highest and was slightly up-regulated in the seeds infected with the WT strain as compared to the $\Delta s p d s$ mutant strain. No significant changes were observed in the expression of other $\mathrm{ZmPao}$ genes.

Among the aflatoxin biosynthetic genes in A. flavus, expression of aflM (AFLA_139300), aflD (AFLA_139390), aflC (AFLA_139410), and aflR (AFLA_139360) was significantly upregulated by $110,350,100$, and 3.5-fold, respectively, in the WT as compared to the $\Delta s p d s$ mutant strain during seed infection (Figures 8C,D). The WT strain $(0.5 \mathrm{mM} \mathrm{Spd})$ had 1.4 to 2.8 fold higher expression of the aflatoxin biosynthetic genes in comparison to the WT strain grown on $\mathrm{CZ}$ agar medium without Spd (prior to the inoculation) during seed infection (Figure 8C).

\section{DISCUSSION}

\section{Ubiquitous Role of PAs in Fungal Growth, Development and Pathogenicity}

Polyamines are ubiquitous in living organisms and are involved in regulating several cellular processes including growth, differentiation, stress response, and pathogenesis (reviewed in Valdés-Santiago et al., 2012; Minocha et al., 2014; MillerFleming et al., 2015). Thus, the PA biosynthetic pathway has often been the target of novel strategies to control diseases associated with fungal and other microbial pathogens (Amano et al., 2015; Burger et al., 2015; Estiarte et al., 2017; Mounce et al., 2017). During the pathogenic interaction between the fungus Colletotrichum truncatum and soybean seeds, application of L- $\alpha$-difluoromethylornithine (DFMO) and difluoromethylarginine (DFMA), inhibitors of Odc and Adc, respectively, reduced intracellular PAs in the fungi and significantly impacted fungal growth (Gamarnik et al., 1994). Exogenous supply of Put or Spd restored fungal growth, suggesting that intracellular contents of Spd might be critical for growth and pathogenesis. The current study, using a gene knock out approach, directly demonstrates that Spd is critical in A. flavus growth, development, pathogenesis, and the production of aflatoxins in vitro; especially during the maize-A. flavus interaction. The $\Delta s p d s$ mutant was an auxotroph for Spd that required an exogenous supply of Spd to partially restore WT levels of growth and sporulation. The inability of Spd supplementation to fully reverse the $\Delta s p d s$ mutation suggested a differential regulation of Spd uptake and distribution in the fungus as compared to its endogenous biosynthesis. Nevertheless, exogenous supply of Spd significantly increased sporulation in the control strain suggesting regulation of sporulation by Spd (Figure 2B). The observation of a 6- to 31-fold higher expression from day 1 to day 2 of A. flavus PA biosynthetic genes (Figure 3B) indicates that there is a high demand for PAs to support the early stages of fungal growth and development. The inability of the $\Delta s p d s$ mutant strain to produce Spd resulted in a significant reduction in fungal growth and aflatoxin production during maize seed infection (Figures 6, 7). The results presented here are in line with earlier reports on the role PAs in fungal development and secondary metabolism. In Fusarium graminearum application of DFMO significantly reduced fungal growth ( $\sim 70 \%)$ and the production of DON by $\sim 53$-fold, under in vitro conditions (Crespo-Sempere et al., 2015). A similar reduction in growth, sporulation, and SM production upon inhibition of Odc or spds knock out were also reported in A. nidulans and A. parasiticus (Khurana et al., 1996; Guzmánde-Peña and Ruiz-Herrerai, 1997; Guzmán-de-Peña et al., 1998; Jin et al., 2002; Khatri and Rajam, 2007). The data presented here demonstrate the role of Spd in A. flavus growth and development in relation to the expression of PA biosynthetic genes and cellular PA content in vitro and during maize seed infection.

\section{Inactivation of Spds Alters Nitrogen Metabolism in the $\Delta$ spds Mutant}

Nitrogen metabolism plays a central role during normal fungal development as well as under stress conditions (Krappmann and Braus, 2005; Valdés-Santiago and Ruiz-Herrera, 2013). PAs can alter overall $\mathrm{N}$ metabolism as the PA biosynthetic pathway is intricately associated with AA biosynthesis (Mohapatra et al., 2010; Beckmann et al., 2013; Majumdar et al., 2013, 2016; Dalton et al., 2016; Wuddineh et al., 2018). Inhibition of Spd biosynthesis 


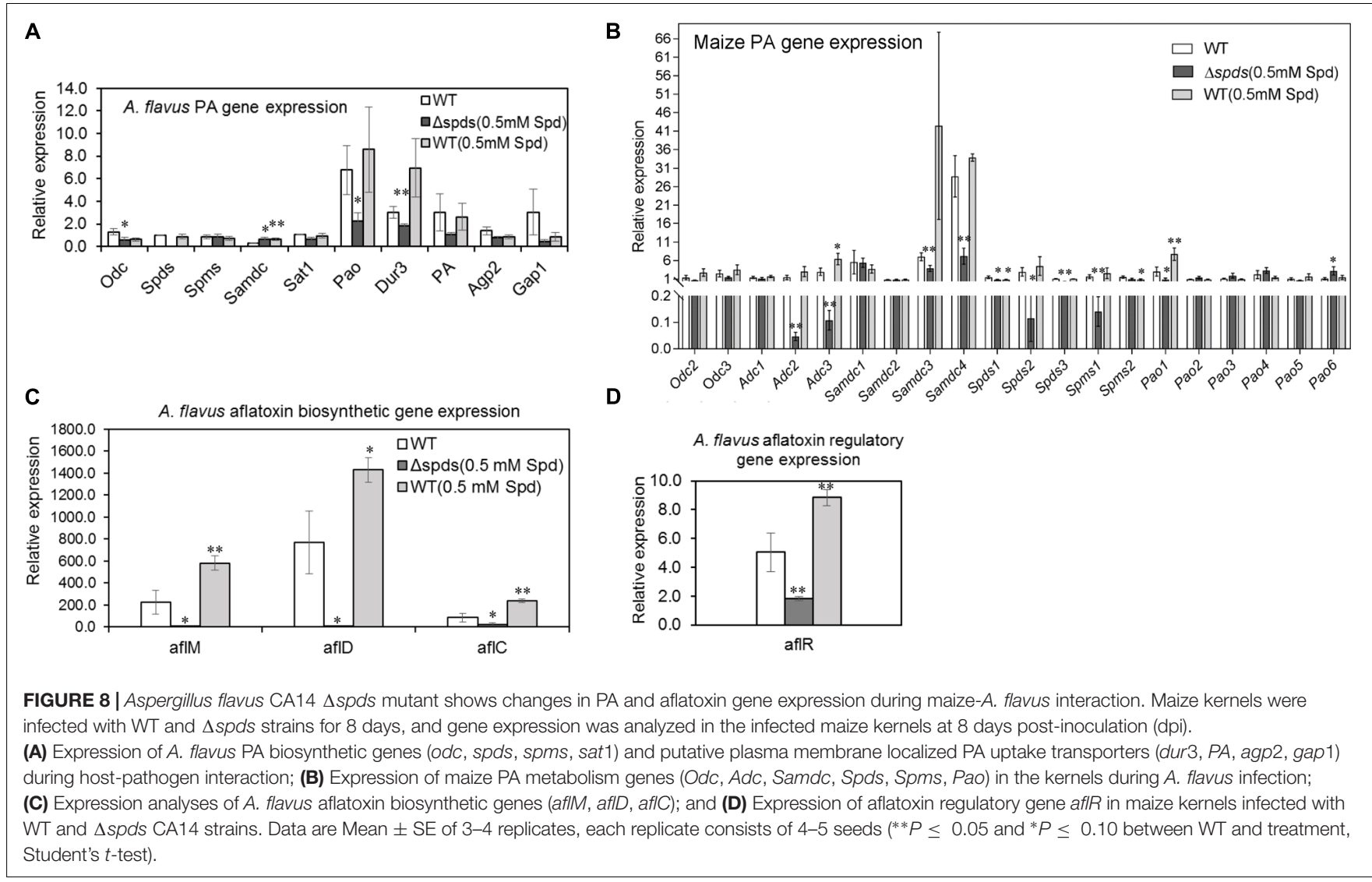

in A. flavus resulted in a significantly higher accumulation of Put ( 2619\%) than the control (Figure 3A). Putrescine overproduction is often accompanied by higher Put catabolism and rapid (within hours) turn-over of Put in plants (Bhatnagar et al., 2002; Shao et al., 2014). This might not be the case in A. flavus as a significant accumulation of Put was observed even after 8 days of culture. This could possibly be due to a greater half-life of Put in the fungus and previous observations that Put can be stored at a very high concentration (under certain conditions) in cells, where it might serve as a source of $\mathrm{N}$ during low $\mathrm{N}$ availability (Middlehoven et al., 1986). The accumulation of Put in the $\Delta s p d s$ mutant of $A$. flavus could be a topic for future studies where radio-labeled PA substrates can be used to study Put turn-over rates and the possible back-conversion of Spd to Put by Sat and Pao enzymes. Other than PAs, intracellular AA content also has a substantial impact on overall $\mathrm{N}$ metabolism in fungi and AAs play an indispensable role in fungal development and pathogenesis. Thus, inhibitors of AA metabolism have been used as antifungal agents (Jastrzebowska and Gabriel, 2015). In the current study, supply of exogenous Spd to the $\Delta s p d s$ mutant revealed that although $A$. flavus resumed growth and sporulation in vitro (albeit lower than the control), intracellular AA content in the mutant was still not on par with the WT strain (Table 1). Alterations in cellular PAs due to inactivation of PA biosynthetic genes ( $s p d s, o d c$ ) in A. nidulans were reported in earlier studies (Jin et al., 2002; Khatri and Rajam, 2007), but the current data show that alterations in Spd levels in A. flavus goes beyond the PA biosynthetic pathway and affects biosynthesis of AAs. Several of the AAs (such as Glu, Ser, Thr) that were decreased in the $\Delta s p d s$ mutant (Table 1) are reported to be critical in fungal pathogenesis (Olivieri et al., 2002; de Sain and Rep, 2015; Muszewska et al., 2017; Zhou et al., 2017). Whether the reduction in pathogenicity in the $\Delta s p d s$ mutant during maize seed infection is due to the decrease in Spd or possible alteration in relative AA content or both, will require further investigation.

\section{Polyamines Modulate Secondary Metabolite (SM) Production}

The PA-hypusine node is critical for cell survival and significantly affects pathogenicity in fungi and other organisms (reviewed in Park et al., 2010; Wolff and Park, 2015). The conversion of a specific Lys residue in the eIF5A to a rare AA hypusine (posttranslational modification) and subsequent activation of eIF5A is absolutely required for cell proliferation. Spd in this regard serves as the only donor of a 4-aminobutyl moiety to the Lys residue of eIF5A carried out by the enzyme deoxyhypusine synthase. The overall effect of Spd depletion on growth and SM production in the $\Delta s p d s$ mutant may be due to a combination of reduced activation of eIF5A leading to reduced fungal growth and direct regulation of SM biosynthesis by Spd (Martinez-Rocha et al., 2016). Supplementation of CZ minimal medium with Spd and to some extent Spm significantly increased the formation of sclerotia and production of aflavinines and aflatrems in AF70 
(Figures 4, 5A). A significant increase in intracellular PA content has been shown to be necessary for sclerotial development in Sclerotinia sclerotiorum (Pieckenstain et al., 2001). The results presented here further demonstrate the direct role of PAs in the production of sclerotia and associated SMs in A. flavus. Besides sclerotial metabolites, production of aflatoxins was also increased by supplementation of the medium with Spd and even greater increases were observed at both concentrations of Spm tested (Figure 5B). The effect of $s p d s$ inactivation $(\Delta s p d s$ mutant) on aflatoxin production was more pronounced during infection of maize seeds where aflatoxin levels were significantly reduced compared to those measured in WT fungal infections (Figure 7). The results obtained from in vitro studies suggest a differential mode of regulation of SM-related gene expression by Spd vs. Spm. Significant up-regulation of the laeA global regulatory gene by Spd supplementation in the growth medium (Figure 5C) and subsequent increase in SM production (Figure 5A), might indicate a possible mode of action of Spd to increase SM production. This observation is in line with the earlier work in Penicillium chrysogenum ( $P$. chrysogenum), where exogenous supply of Spd or 1,3-diaminopropane (1,3DAP; a catabolic product of Spd) to the laeA knockdown mutant (produces very low amounts of benzyl-penicillin) significantly increased the expression of penicillin biosynthetic genes and completely restored the production of benzyl-penicillin in the laeA mutant to WT levels (Martin et al., 2012). An observed increase in the levels of other uncharacterized A. flavus SMs upon supplementation of media with Spd also points to PAs having the capacity to potentially activate silent metabolic gene clusters (data not shown). Biochemical characterization of these SMs could be of interest for future studies. Expression of $v e A$ and $n s d C$, global regulators of development and secondary metabolism in A. flavus (Cary et al., 2007, 2012; Duran et al., 2007), were also studied with respect to their regulation by PAs. Expression of $n s d C$ was slightly increased by Spd whereas both Spd and Spm slightly repressed the expression of $v e A$ (Figure 5C). Future RNA-seq studies using the A. flavus $\Delta s p d s$ mutant will help in understanding the global regulation of gene expression by Spd as it relates to growth, development, pathogenicity, and the production of SMs.

\section{PA Uptake and Biosynthesis Plays a Key Role in Fungal Pathogenesis}

Polyamine transport in fungi plays a major role in fungal growth during host-pathogen interactions (reviewed in Valdés-Santiago et al., 2012; Miller-Fleming et al., 2015; Estiarte et al., 2017). In the model fungus Saccharomyces cerevisiae, among several plasma membrane localized transporters, Dur3, Sam3, Agp2, and Gap1 are reported to be involved in PA uptake from the external environment with Dur3 and Sam3 being the major importers of extracellular PAs (Aouida et al., 2005, 2013; Uemura et al., 2005, 2007). In A. nidulans, Put uptake is 2- to 3-fold more rapid than the uptake of Spd (Spathas et al., 1982) and uptake of Spd was inhibited by increased concentrations of Put and Spm. However, Put uptake was not affected by the presence of Spd or Spm. Expression analyses of PA genes and transporters in A. flavus during maize seed infection showed a significant increase in the expression of putative PA uptake (Put?) transporter dur3 (AFLA_029660) in the WT compared to the $\Delta s p d s$ mutant indicating an important role for PA uptake by the fungus to achieve successful pathogenesis (Figure 8A). The fact that Put content increases several-fold in plants during fungal infection and uptake of Put is more efficient than other PAs (Spathas et al., 1982; Wojtasik et al., 2015), it is likely that Put is the predominant PA that the fungus might uptake from the plant host. Application of biochemical inhibitors of putative plasma membrane localized PA uptake transporters and significant reduction in fungal infection and DON production (reduced 124-fold) were reported during infection of wheat spikelets by F. graminearum (Crespo-Sempere et al., 2015). Similar results on inhibition of PA transport and reduction in fungal pathogenicity in vitro and in vivo were reported for Alternaria alternata infection of tomato (Estiarte et al., 2017). Among the expression of different PA metabolism genes that were studied during the maize-A. flavus interaction, the expression of $\mathrm{ZmSamdc}$ genes was the highest followed by $\mathrm{ZmAdc}$ genes, that significantly increased in the maize kernels following inoculation with the WT A. flavus strain compared to the $\Delta s p d s$ mutant (Figure $\mathbf{8 B}$ ). This suggested differential responses in maize Put biosynthesis and production of higher PAs with respect to virulent vs. less virulent strains of the same pathogen. Similar differential induction of Put biosynthesis by Odc (higher against virulent strain) in flax seedlings was observed when they were exposed to virulent and avirulent strains of Fusarium culmorum and Fusarium oxysporum, respectively (Wojtasik et al., 2015). Significant increase in the expression of maize Samdc and $A d c$ genes were also reported in leaves infected by the fungal pathogen Ustilago maydis (RodríguezKessler et al., 2008). Overall the results presented here suggest that up-regulation of PA uptake transporters in A. flavus during infection of maize leads to PA uptake from the host though this cannot fully compensate for Spd depletion in the $\Delta s p d s$ mutant.

\section{CONCLUSION}

Polyamine metabolism plays a significant role in host defense and also in maintaining successful pathogenesis in fungi (and in other pathogens) during the host-pathogen interaction. The results presented here demonstrate the role of Spd in A. flavus growth, development, and SM production both in vitro and in vivo. Abrogation of intracellular Spd biosynthesis in A. flavus negatively affected fungal growth, expression of PA biosynthetic genes, and aflatoxin biosynthesis during maize seed infection. Increase in overall SM production in A. flavus by an exogenous supply of Spd (in vitro) also supports the role of Spd in SM production. Significant up-regulation of A. flavus plasma membrane-localized PA uptake transporters during maize seed infection suggests that dual targeting of PA uptake transporters and spds through an RNAi- based approach or application of biochemical inhibitors, might be an effective strategy to control A. flavus colonization and aflatoxin production in maize and other susceptible food crops. 


\section{AUTHOR CONTRIBUTIONS}

RMa, JC, SM, and KR: conceived and designed the experiments. $\mathrm{RMa}, \mathrm{BM}$, and CS: performed the experiments. RMa, ML, RMi, SM, and CC-W: analyzed the data. RMa, ML, and RMi: wrote the paper. JC, RMi, SM, and KR: edited the draft manuscript. All authors reviewed and approved the final manuscript.

\section{FUNDING}

This research was funded by the United States Department of Agriculture, Agricultural Research Service (No. 605441420-008-00D). Partial funding was provided by the New Hampshire Agricultural Experiment Station (scientific contribution number 2765). The funding for this research was also provided in part by USDA Forest Service. This work was supported by the USDA National Institute

\section{REFERENCES}

Amano, Y., Namatame, I., Tateishi, Y., Honboh, K., Tanabe, E., Niimi, T., et al. (2015). Structural insights into the novel inhibition mechanism of Trypanosoma cruzi spermidine synthase. Acta Crystallogr. D Biol. Crystallogr. 71, 1879-1889. doi: 10.1107/S1399004715013048

Aouida, M., Leduc, A., Poulin, R., and Ramotar, D. (2005). AGP2 encodes the major permease for high affinity polyamine import in Saccharomyces cerevisiae. J. Biol. Chem. 280, 24267-24276. doi: 10.1074/jbc.M503071200

Aouida, M., Rubio-Texeira, M., Thevelein, J. M., Poulin, R., and Ramotar, D. (2013). Agp2, a member of the yeast amino acid permease family, positively regulates polyamine transport at the transcriptional level. PLoS One 8:e65717. doi: 10.1371/journal.pone.0065717

Beckmann, N., Schafferer, L., Schrettl, M., Binder, U., Talasz, H., Lindner, H., et al. (2013). Characterization of the link between ornithine, arginine, polyamine and siderophore metabolism in Aspergillus fumigatus. PLoS One 8:e67426. doi: 10.1371 /journal.pone.0067426

Bhatnagar, P., Minocha, R., and Minocha, S. C. (2002). Genetic manipulation of the metabolism of polyamines in poplar cells. The regulation of putrescine catabolism. Plant Physiol. 128, 1455-1469. doi: 10.1104/pp. 010792

Burger, P. B., Williams, M., Sprenger, J., Reeksting, S. B., Botha, M., Müller, I. B., et al. (2015). A novel inhibitor of Plasmodium falciparum spermidine synthase: a twist in the tail. Malar. J. 14, 54. doi: 10.1186/s12936-015-0572-z

Cary, J. W., Ehrlich, K., Bland, J. M., and Montalbano, B. (2006). The aflatoxin biosynthesis cluster gene AflX, encodes an oxidoreductase involved in conversion of versicolorin A to demethylsterigmatocystin. Appl. Environ. Microbiol. 72, 1096-1101. doi: 10.1128/AEM.72.2.1096-1101. 2006

Cary, J. W., Gr, O. B., Nielsen, D. M., Nierman, W., Harris-Coward, P., Yu, J., et al. (2007). Elucidation of veA-dependent genes associated with aflatoxin and sclerotial production in Aspergillus flavus by functional genomics. Appl. Microbiol. Biotechnol. 76, 1107-1118. doi: 10.1007/s00253-007-1081-y

Cary, J. W., Harris-Coward, P. Y., Ehrlich, K. C., Mack, B. M., Kale, S. P., Larey, C., et al. (2012). NsdC and NsdD affect Aspergillus flavus morphogenesis and aflatoxin production. Eukaryot. Cell 11, 1104-1111. doi: 10.1128/EC.00069-12

Cary, J. W., Uka, V., Han, Z., Buyst, D., Harris-Coward, P. Y., Ehrlich, K. C., et al. (2015). An Aspergillus flavus secondary metabolic gene cluster containing a hybrid PKS-NRPS is necessary for synthesis of the 2-pyridones, leporins. Fungal Genet. Biol. 81, 88-97. doi: 10.1016/j.fgb.2015.05.010

Crespo-Sempere, A., Estiarte, N., Marin, S., Sanchis, V., and Ramos, A. J. (2015). Targeting Fusarium graminearum control via polyamine enzyme inhibitors and polyamine analogs. Food Microbiol. 49, 95-103. doi: 10.1016/j.fm.2015.01.020

Dalton, H. L., Blomstedt, C. K., Neale, A. D., Gleadow, R., Deboer, K. D., and Hamill, J. D. (2016). Effects of down-regulating ornithine decarboxylase upon of Food and Agriculture (McIntire-Stennis) Project (NH00076-M).

\section{ACKNOWLEDGMENTS}

The authors acknowledge the help of Ms. Stephanie Long in processing fungal samples for amino acids analyses. They also acknowledge help from Ms. Mary Lovisa and Ms. Kelley Williams.

\section{SUPPLEMENTARY MATERIAL}

The Supplementary Material for this article can be found online at: https://www.frontiersin.org/articles/10.3389/fpls.2018.00317/ full\#supplementary-material

putrescine-associated metabolism and growth in Nicotiana tabacum L. J. Exp. Bot. 67, 3367-3381. doi: 10.1093/jxb/erw166

de Sain, M., and Rep, M. (2015). The role of pathogen-secreted proteins in fungal vascular wilt diseases. Int. J. Mol. Sci. 16, 23970-23993. doi: 10.3390/ ijms161023970

Duran, R. M., Cary, J. W., and Calvo, A. M. (2007). Production of cyclopiazonic acid, aflatrem, and aflatoxin by Aspergillus flavus is regulated by veA, a gene necessary for sclerotial formation. Appl. Microbiol. Biotechnol. 73, 1158-1168. doi: 10.1007/s00253-006-0581-5

Estiarte, N., Crespo-Sempere, A., Marin, S., Sanchis, V., and Ramos, A. J. (2017). Exploring polyamine metabolism of Alternaria alternata to target new substances to control the fungal infection. Food Microbiol. 65, 193-204. doi: 10.1016/j.fm.2017.02.001

Farfan, I. D., De La Fuente, G. N., Murray, S. C., Isakeit, T., Huang, P. C., Warburton, M., et al. (2015). Genome wide association study for drought, aflatoxin resistance, and important agronomic traits of maize hybrids in the sub-tropics. PLoS One 10:e0117737. doi: 10.1371/journal.pone.0117737

Fountain, J. C., Bajaj, P., Pandey, M., Nayak, S. N., Yang, L., Kumar, V., et al. (2016). Oxidative stress and carbon metabolism influence Aspergillus flavus secondary metabolite production and transcriptome composition. Sci. Rep. 6:38747. doi: $10.1038 /$ srep38747

Fountain, J. C., Khera, P., Yang, L., Nayak, S. N., Scully, B. T., Lee, R. D., et al. (2015). Resistance to Aspergillus flavus in maize and peanut: molecular biology, breeding, environmental stress, and future perspectives. Crop J. 3, 229-237. doi: 10.1016/j.cj.2015.02.003

Fountain, J. C., Scully, B. T., Ni, X., Kemerait, R. C., Lee, R. D., Chen, Z. Y., et al. (2014). Environmental influences on maize-Aspergillus flavus interactions and aflatoxin production. Front. Microbiol. 5:40. doi: 10.3389/fmicb.2014.00040

Gamarnik, A., Frydman, R. B., and Barreto, D. (1994). Prevention of infection of soybeanseeds by Colletotrichum truncatum by polyamine biosynthesis inhibitors. Phytopathology 84, 1445-1448. doi: 10.1094/Phyto-84-1445

Gardiner, D. M., Kazan, K., and Manners, J. M. (2009). Nutrient profiling reveals potent inducers of trichothecene biosynthesis in Fusarium graminearum. Fungal Genet. Biol. 46, 604-613. doi: 10.1016/j.fgb.2009.04.004

Gardiner, D. M., Kazan, K., Praud, S., Torney, F. J., Rusu, A., and Manners, J. M. (2010). Early activation of wheat polyamine biosynthesis during Fusarium head blight implicates putrescine as an inducer of trichothecene mycotoxin production. BMC Plant Biol. 10:289. doi: 10.1186/1471-2229-10-289

Guzmán-de-Peña, D., Aguirre, J., and Ruiz-Herrera, J. (1998). Correlation between the regulation of sterigmatocystin biosynthesis and asexual and sexual sporulation in Emericella nidulans. Antonie Leeuwenhoek 73, 199-205. doi: 10.1023/A:1000820221945

Guzmán-de-Peña, D., and Ruiz-Herrerai, J. (1997). Relationship between aflatoxin biosynthesis and sporulation in Aspergillus parasiticus. Fungal Genet. Biol. 21, 198-205. doi: 10.1006/fgbi.1996.0945 
Hamidou, F., Rathore, A., Waliyar, F., and Vadez, V. (2014). Although drought intensity increases aflatoxin contamination, drought tolerance does not lead to less aflatoxin contamination. Field Crop Res. 156, 103-110. doi: 10.1016/j.fcr. 2013.10.019

Ismaiel, A., and Papenbrock, J. (2015). Mycotoxins: producing fungi and mechanisms of phytotoxicity. Agriculture 5, 492-537. doi: 10.3390/ agriculture 5030492

Jasso-Robles, F. I., Jiménez-Bremont, J. F., Becerra-Flora, A., Juárez-Montiel, M., Gonzalez, M. E., Pieckenstain, F. L., et al. (2016). Inhibition of polyamine oxidase activity affects tumor development during the maize-Ustilago maydis interaction. Plant Physiol. Biochem. 102, 115-124. doi: 10.1016/j.plaphy.2016. 02.019

Jastrzebowska, K., and Gabriel, I. (2015). Inhibitors of amino acids biosynthesis as antifungal agents. Amino Acids 47, 227-249. doi: 10.1007/s00726-0141873-1

Jin, Y., Bok, J. W., Guzman-De-Peña, D., and Keller, N. P. (2002). Requirement of spermidine for developmental transitions in Aspergillus nidulans. Mol. Microbiol. 46, 801-812. doi: 10.1046/j.1365-2958.2002.03201.x

Kebede, H., Abbas, H. K., Fisher, D. K., and Bellaloui, N. (2012). Relationship between aflatoxin contamination and physiological responses of corn plants under drought and heat stress. Toxins 4, 1385-1403. doi: 10.3390/ toxins 4111385

Khatri, M., and Rajam, M. V. (2007). Targeting polyamines of Aspergillus nidulans by siRNA specific to fungal ornithine decarboxylase gene. Med. Mycol. 45, 211-220. doi: 10.1080/13693780601158779

Khurana, N., Saxena, R. K., Gupta, R., and Rajam, M. V. (1996). Poylamines as modulators of microcycle conidiation in Aspergillus flavus. Microbiology 142, 517-523. doi: 10.1099/13500872-142-3-517

Krappmann, S., and Braus, G. H. (2005). Nitrogen metabolism of Aspergillus and its role in pathogenicity. Med. Mycol. 43, 31-40. doi: 10.1080/ 13693780400024271

Kummasook, A., Cooper, C. R. Jr., Sakamoto, A., Terui, Y., Kashiwagi, K., and Vanittanakom, N. (2013). Spermidine is required for morphogenesis in the human pathogenic fungus, Penicillium marneffei. Fungal Genet. Biol. 5, 25-32. doi: 10.1016/j.fgb.2013.08.001

Liao, Z., ZhangGuan, X., Zhu, Z., Yao, X. W., Yang, Y., Jiang, Y. Y., et al. (2015). Enhancement of the antibiofilm activity of amphotericin B by polyamine biosynthesis inhibitors. Int. J. Antimicrob. Agents 46, 45-52. doi: 10.1016/j. ijantimicag.2015.02.021

Livak, K. J., and Schmittgen, T. D. (2001). Analysis of relative gene expression data using real-time quantitative PCR and the $2^{-\Delta \Delta C_{\mathrm{T}}}$ method. Methods 25, 402-408. doi: 10.1006/meth.2001.1262

Majumdar, R., Barchi, B., Turlapati, S. A., Gagne, M., Minocha, R., Long, S., et al. (2016). Glutamate, ornithine, arginine, proline, and polyamine metabolic interactions: the pathway is regulated at the post-transcriptional level. Front. Plant Sci. 7:78. doi: 10.3389/fpls.2016.00078

Majumdar, R., Minocha, R., and Minocha, S. C. (2015). "Ornithine: at the crossroads of multiple paths to amino acids and polyamines," in Amino Acids in Higher Plants, ed. J. P. F. D'mello (Wallingford, CT: CABI), 156-176.

Majumdar, R., Shao, L., Minocha, R., Long, S., and Minocha, S. C. (2013). Ornithine: the overlooked molecule in the regulation of polyamine metabolism. Plant Cell Physiol. 54, 990-1004. doi: 10.1093/pcp/pct053

Martin, J., Garcia-Estrada, C., Kosalkova, K., Ullan, R. V., Albillos, S. M., and Martin, J. F. (2012). The inducers 1,3-diaminopropane and spermidine produce a drastic increase in the expression of the penicillin biosynthetic genes for prolonged time, mediated by the laeA regulator. Fungal Genet. Biol. 49, 10041013. doi: 10.1016/j.fgb.2012.10.001

Martinez-Rocha, A. L., Woriedh, M., Chemnitz, J., Willingmann, P., Kroger, C., Hadeler, B., et al. (2016). Posttranslational hypusination of the eukaryotic translation initiation factor-5A regulates Fusarium graminearum virulence. Sci. Rep. 6:24698. doi: 10.1038/srep24698

Masson, P. H., Takahashi, T., and Angelini, R. (2017). Editorial: molecular mechanisms underlying polyamine functions in plants. Front. Plant Sci. 8:14. doi: 10.3389/fpls.2017.00014.

Mateles, R. I., and Adye, J. C. (1965). Productions of aflatoxins in submerged culture. Appl. Microbiol. 13, 208-211.

Middlehoven, W. J., Hoogkamer-Te Niet, M. C., De Laat, W. T. A. M., Weijers, C., and Bulder, C. J. E. A. (1986). Oxidation of amines by yeasts grown on 1-aminoalkanes or putrescine as the sole source of carbon, nitrogen and energy. Antonie Van Leeuwenhoek 52, 525-536. doi: 10.1007/BF00423413

Miller-Fleming, L., Olin-Sandoval, V., Campbell, K., and Ralser, M. (2015). Remaining mysteries of molecular biology: the role of polyamines in the cell. J. Mol. Biol. 427, 3389-3406. doi: 10.1016/j.jmb.2015.06.020

Minocha, R., and Long, S. (2004). Simultaneous separation and quantitation of amino acids and polyamines of forest tree tissues and cell cultures within a single high-performance liquid chromatography run using dansyl derivatization. J. Chromatogr. A 1035, 63-73. doi: 10.1016/j.chroma.2004. 02.026

Minocha, R., Majumdar, R., and Minocha, S. C. (2014). Polyamines and abiotic stress in plants: a complex relationship. Front. Plant Sci. 5:175. doi: 10.3389/ fpls.2014.00175

Mitchell, N., Bowers, E., Hurburgh, C., and Wu, F. (2016). Potential economic losses to the USA corn industry from aflatoxin contamination. Food Addit. Contam. Part A 33, 540-550. doi: 10.1080/19440049.2016.1138545

Mohapatra, S., Minocha, R., Long, S., and Minocha, S. C. (2010). Transgenic manipulation of a single polyamine in poplar cells affects the accumulation of all amino acids. Amino Acids 38, 1117-1129. doi: 10.1007/s00726-009-0322-z

Mounce, B. C., Olsen, M. E., Vignuzzi, M., and Connor, J. H. (2017). Polyamines and their role in virus infection. Microbiol. Mol. Biol. Rev. 81:e00029-17. doi: 10.1128/MMBR.00029-17

Mueller, E., Bailey, A., Corran, A., Michael, A. J., and Bowyer, P. (2001). Ornithine decarboxylase knockout in Tapesia yallundae abolishes infection plaque formation in vitro but does not reduce virulence toward wheat. Mol. Plant Microbe Interact. 14, 1303-1311. doi: 10.1094/MPMI.2001.14.11. 1303

Muszewska, A., Stepniewska-Dziubinska, M. M., Steczkiewicz, K., Pawlowska, J., Dziedzic, A., and Ginalski, K. (2017). Fungal lifestyle reflected in serine protease repertoire. Sci. Rep. 7:9147. doi: 10.1038/s41598-017-09644-w

Olivieri, F., Zanetti, M. E., Oliva, C. R., Covarrubias, A. A., and Casalongué, C. A. (2002). Characterization of an extracellular serine protease of Fusarium eumartii and its action on pathogenesis related proteins. Eur. J. Plant Pathol. 108, 63-72. doi: 10.1023/A:1013920929965

Park, M. H., Nishimura, K., Zanelli, C. F., and Valentini, S. R. (2010). Functional significance of eIF5A and its hypusine modification in eukaryotes. Amino Acids 38, 491-500. doi: 10.1007/s00726-009-0408-7

Pieckenstain, F. L., G'Arriz, A. E., Chornomaz, E. M., S'Anchez, D. H., and Ruiz, O. A. (2001). The effect of polyamine biosynthesis inhibition on growth and differentiation of the phytopathogenic fungus Sclerotinia sclerotiorum. Antonie Van Leeuwenhoek 80, 245-253. doi: 10.1023/A:1013021011328

Rajasekaran, K., Sickler, C. M., Brown, R. L., Cary, J. W., and Bhatnagar, D. (2013). Evaluation of resistance to aflatoxin contamination in kernels of maize genotypes using a GFP-expressing Aspergillus flavus strain. World Mycotoxin J. 6, 151-158. doi: 10.3920/WMJ2012.1497

Rodríguez-Kessler, M., Ruiz, O. A., Maiale, S., Ruiz-Herrera, J., and JiménezBremont, J. F. (2008). Polyamine metabolism in maize tumors induced by Ustilago maydis. Plant Physiol. Biochem. 46, 805-814. doi: 10.1016/j.plaphy. 2008.05.012

Shao, L., Bhatnagar, P., Majumdar, R., Minocha, R., and Minocha, S. C. (2014). Putrescine overproduction does not affect the catabolism of spermidine and spermine in poplar and Arabidopsis. Amino Acids 46, 743-757. doi: 10.1007/ s00726-013-1581-2

Shao, L., Majumdar, R., and Minocha, S. C. (2012). Profiling the aminopropyltransferases in plants: their structure, expression and manipulation. Amino Acids 42, 813-830. doi: 10.1007/s00726-011-0998-8

Shu, X., Livingston, D. P., Franks, R. G., Boston, R. S., Woloshuk, C. P., and Payne, G. A. (2015). Tissue-specific gene expression in maize seeds during colonization by Aspergillus flavus and Fusarium verticillioides. Mol. Plant Pathol. 16, 662-674. doi: 10.1111/mpp.12224

Spathas, D. H., Patemans, J. A., and Clutterbuck, A. J. (1982). Polyamine transport in Aspergillus nidulans. J. Gen. Microbiol. 128, 557-563. doi: 10.1099/00221287128-3-557

Szewczyk, E., Nayak, T., Oakley, C. E., Edgerton, H., Xiong, Y., and TaheriTalesh, N. (2006). Fusion PCR and gene targeting in Aspergillus nidulans. Nat. Protoc. 1, 3111-3120. doi: 10.1038/nprot.2006.405

Takahashi, Y. (2016). The role of polyamines in plant disease resistance. Environ. Control Biol. 54, 17-21. doi: 10.2525/ecb.54.17 
Thakare, D., Zhang, J., Wing, R. A., Cotty, P. J., and Schmidt, M. A. (2017). Aflatoxin-free transgenic maize using host-induced gene silencing. Sci. Adv. 3:e1602382. doi: $10.1126 /$ sciadv. 1602382

Uemura, T., Kashiwagi, K., and Igarashi, K. (2005). Uptake of putrescine and spermidine by Gaplp on the plasma membrane in Saccharomyces cerevisiae. Biochem. Biophys. Res. Commun. 328, 1028-1033. doi: 10.1016/j.bbrc.2005. 01.064

Uemura, T., Kashiwagi, K., and Igarashi, K. (2007). Polyamine uptake by DUR3 and SAM3 in Saccharomyces cerevisiae. J. Biol. Chem. 282, 7733-7741. doi: 10.1074/jbc.M611105200

Umesha, S., Manukumar, H. M., Chandrasekhar, B., Shivakumara, P., Shiva Kumar, J., Raghava, S., et al. (2016). Aflatoxins and food pathogens: impact of biologically active aflatoxins and their control strategies. J. Sci. Food Agric. 97, 1698-1707. doi: 10.1002/jsfa.8144

Valdés-Santiago, L., Cervantes-Chavez, J. A., Leon-Ramirez, C. G., and RuizHerrera, J. (2012). Polyamine metabolism in fungi with emphasis on phytopathogenic species. J. Amino Acids 2012, 837932. doi: 10.1155/2012/ 837932

Valdés-Santiago, L., and Ruiz-Herrera, J. (2013). Stress and polyamine metabolism in fungi. Front. Chem. 1:42. doi: 10.3389/fchem.2013.00042

Wojtasik, W., Kulma, A., Namysl, K., Preisner, M., and Szopa, J. (2015). Polyamine metabolism in flax in response to treatment with pathogenic and nonpathogenic Fusarium strains. Front. Plant Sci. 6:291. doi: 10.3389/fpls.2015. 00291
Wolff, E. C., and Park, M. H. (2015). "Role of the polyamine spermidine as a precursor for hypusine modification in eIF5A," in Polyamines, eds T. Kusano and H. Suzuki (Tokyo: Springer), 121-129. doi: 10.1007/978-4-431-55 212-3_10

Wuddineh, W., Minocha, R., and Minocha, S. C. (2018). "Polyamines in the context of metabolic networks," in Polyamines: Methods and Protocols, Methods in Molecular Biology, eds R. Alcázar and A. Tiburcio (Springer), 1-23.

Zhou, W., Shi, W., Xu, X. W., Li, Z. G., Yin, C. F., Peng, J. B., et al. (2017). Glutamate synthase MoGlt1-mediated glutamate homeostasis is important for autophagy, virulence and conidiation in the rice blast fungus. Mol. Plant Pathol. 19, 564-578. doi: 10.1111/mpp. 12541

Conflict of Interest Statement: The authors declare that the research was conducted in the absence of any commercial or financial relationships that could be construed as a potential conflict of interest.

Copyright (c) 2018 Majumdar, Lebar, Mack, Minocha, Minocha, Carter-Wientjes, Sickler, Rajasekaran and Cary. This is an open-access article distributed under the terms of the Creative Commons Attribution License (CC BY). The use, distribution or reproduction in other forums is permitted, provided the original author(s) and the copyright owner are credited and that the original publication in this journal is cited, in accordance with accepted academic practice. No use, distribution or reproduction is permitted which does not comply with these terms. 